\title{
Roman dogs from the Iberian Peninsula and the Maghreb - A glimpse into their morphology and genetics
}

\author{
Ana Elisabete Pires a, b, c, *, Cleia Detry ${ }^{\text {c }}$, Carlos Fernandez-Rodriguez ${ }^{\mathrm{d}}$, \\ Silvia Valenzuela-Lamas ${ }^{\mathrm{e}}$, Ana Margarida Arruda ${ }^{\mathrm{c}}$, Jacopo De Grossi Mazzorin ${ }^{\mathrm{f}}$, \\ Morgane Ollivier ${ }^{\mathrm{g}, 1}{ }^{\text {, }}$ Catherine Hänni ${ }^{\mathrm{h}}$, Fernanda Simões ${ }^{\mathrm{i}}$, Catarina Ginja ${ }^{\mathrm{b}}$ \\ a LARC - Laboratório de Arqueociências, Direcção Geral do Património Cultural, Lisboa, Portugal \\ b CIBIO-InBIO, Centro de Investigação em Biodiversidade e Recursos Genéticos, Universidade do Porto, Vairão, Portugal \\ ${ }^{c}$ UNIARQ - Centro de Arqueologia da Universidade de Lisboa, Faculdade de Letras de Lisboa. Universidade de Lisboa, Portugal \\ ${ }^{\mathrm{d}}$ Departamento de Historia, Facultad de Filosofía y Letras, Universidad de León, Léon, Spain

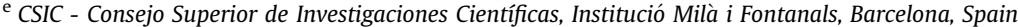 \\ ${ }^{\mathrm{f}}$ Università del Salento, Lecce, Italy \\ g CNRS-ENS, French National Platform of Paleogenetics, PALGENE, Ecole Normale Supérieure de Lyon, Lyon, France \\ ${ }^{\mathrm{h}}$ LECA - Laboratoire d'Ecologie Alpine, Université Grenoble Alpes, Grenoble, France \\ ${ }^{\mathrm{i}}$ Instituto Nacional de Investigação Agrária e Veterinária, I.P., Lisboa, Portugal
}

\section{A R T I C L E I N F O}

\section{Article history:}

Received 23 January 2017

Received in revised form

27 November 2017

Accepted 29 November 2017

Available online $\mathrm{xxx}$

\begin{abstract}
A B S T R A C T
In this study, we integrate osteometric and palaeogenetic data to investigate dog variability in the Roman Empire in Iberia and North Africa. Osteometry was used to distinguish the status-domestic or wild, of approximately 2000 years old Canis remains and to understand to what extent teeth and long bones varied in dogs in the Roman provinces of Mauretania Tingitana, Lusitania and Tarraconensis. Highthroughput 454-DNA sequencing technology was used to obtain mitochondrial DNA (mtDNA) sequences from 15 bone and teeth samples. We identified five dog haplotypes from partial sequences of the hypervariable D-loop region. MtDNA haplotypes were grouped into two of the four major clades found in present-day dogs. We detected three clade A haplotypes in 12 samples from Portugal, Spain and Morocco, and a single clade D haplotype in 3 samples from Spain. So far, this is the oldest evidence for the presence of dog clade D in Iberia. It is dated to the late Roman occupation in the 4th-5th cent. AD (ca. 1,600 years ago).

Our results confirm the existence of distinct dog morphotypes in Roman times that also harboured distinct genetic lineages. According to our data, dogs from distinct mtDNA lineages (clades A and D) have been continuously bred in the Iberian Peninsula since at least 1600 years ago. Moreover, the sharing of matrilines between dogs from Spain and North Africa may indicate gene flow. Dogs could have been easily transported between these regions by humans along maritime and terrestrial trade routes. These results provide new insights into pre-Roman and Roman domestication practices, confirming selection practices were extensively applied to dogs during the first centuries of our era in the Iberian Peninsula. We show that the greater size variability of teeth length (and consequently cranium) and long bone breadths (and consequently phenotype) of Roman dogs in the Iberian Peninsula, is concomitant with the detection of diverse and rare maternal lineages. This would reflect an intensification of dog breeding and the use of non-local dogs for breeding.
\end{abstract}

๑๑ 2017 Elsevier Ltd and INQUA. All rights reserved.

\footnotetext{
* Corresponding author. Laboratório de Arqueociências (LARC) / DGPC and CIBIO / InBIO - EnvArch group, Rua da Bica do Marquês (à Ajuda), nº 2, 1300-087, Lisboa, Portugal.

E-mail address: ana.elisabete.pires@gmail.com (A.E. Pires).

1 Present address: UMR CNRS 6553 Ecobio, OSUR (Observatoire des Sciences de l'Univers de Rennes), University of Rennes 1, Rennes Cedex, France.
}

\section{Introduction}

Dogs (Canis lupus familiaris), the oldest domesticate, show huge morphological variability today. But when did this domestic animal begin to vary so much in size and shape? A variety of dog statures, with small dogs having a withers height less than $30 \mathrm{~cm}$ and others 
over $60 \mathrm{~cm}$, have been reported from the Late Glacial Period $c a$. 18,000-10,000 years ago (Horard-Herbin et al., 2014). Although not as variable as extant dogs, greater variability in both size and shape is also well known in dogs from Roman times ca. 2,000 years ago (Altuna and Mariezkurrena, 1992; Bennett et al., 2016; Colominas, 2015; De Grossi Mazzorin and Tagliacozzo, 2000; MacKinnon, 2010; Peters, 1998). This process probably originated in preceding times, i.e., in the late Iron Age ca. 2,500 years ago (Bennett et al., 2016), but the very small lap, or toy dogs, appear for the first time, and in large numbers, throughout the Roman Empire ca. 2,000 years ago (e.g, Boessneck and von den Driesch, 1980; Altuna and Mariezkurrena, 1992; Fernández-Rodriguez, 2003; MacKinnon, 2010). In the Western Mediterranean, the differentiation of dog populations into different phenotypes similar to breeds may have its roots in the Roman period (De Grossi Mazzorin and Tagliacozzo, $2000,1998)$. In fact, the extent of morphological variation is most evident in Roman times and today-perhaps because artificial selection was and is extensively exercised over dogs by humans for aesthetic/emotional reasons (e.g. dogs just for companionship such as lap dogs) and not only for functional/working purposes (dogs used for hunting or herding). The definition of today's dog breeds follows criteria defined in the 19th century AD and it is not possible to recognize extant dog breeds in ancient periods merely through osteological morphology (Harcourt, 1974; Morales et al., 2015). Nevertheless, Varro in his De re rustica book (1st cent. AD) provided a dog classification based on their function.

Coat colour also varied since early times. The investigation of molecular markers associated with dark versus light coat colour, i.e., $M c 1 r$ (melanocortin 1 receptor) and CBD103 (canine- $\beta$-defen$\sin$ ) genes, showed the presence of dogs with light and dark coat colours as early as the beginning of the Mesolithic, over 8000 years ago (Ollivier et al., 2013). Well known Roman iconography-mosaic floors and wall paintings-confirm a diversity of morphologies and coat colours in dogs (Fig. 1). The dog morphotypes represented in mosaics do not necessarily reflect local dogs, as the artisans tended to move around the Empire possibly producing representations of what they had seen in other places; however, in the Roman city of Conímbriga, in Lusitania, Portugal, there are indications that the artisans were local (Correia, 2013). Thus, it is probable that these dog morphotypes existed across the Roman Empire.

Zooarchaeological studies aid our understanding of size and morphological variation in Roman Canis (e.g., Altuna and Mariezkurrena, 1992; Bennett et al., 2016; Colominas, 2015; MacKinnon, 2010). The various anatomical parts are preserved differently in the archaeological record. For instance, the first molar tooth $-\mathrm{M}_{1}-$ is frequently found intact in the archaeological record. However, the $M_{1}$ length variability is not necessarily correlated with body size, but it reflects to some extent the cranium size and shortening of the snout. This latter characteristic is a marker of the domestication process, since dogs tend to have shorter snouts than wolves (Tchernov and Valla, 1997). Measurements of the long bones (femura) are a better proxy for the overall body size variability (Wayne, 2001) and therefore can indicate the presence of different morphotypes. However, in the archaeological record these bones are frequently found fragmented.

Genetic studies using ancient DNA (aDNA) can provide important insights into the understanding of population genetics, gene flow and human-driven selection for certain traits in animals of the past (Botigué et al., 2017; Ollivier et al., 2016, 2013; Pilot et al., 2014; Svensson et al., 2007), particularly when bones are morphologically indistinct. However, these kinds of studies are still scarce for Roman material, particularly in the Iberian Peninsula, a region where samples tend to be poorly preserved (but see Catagnano, 2016). Mitochondrial DNA (mtDNA) has been particularly useful for studying the genetic composition of archaeological specimens (e.g.,
A)

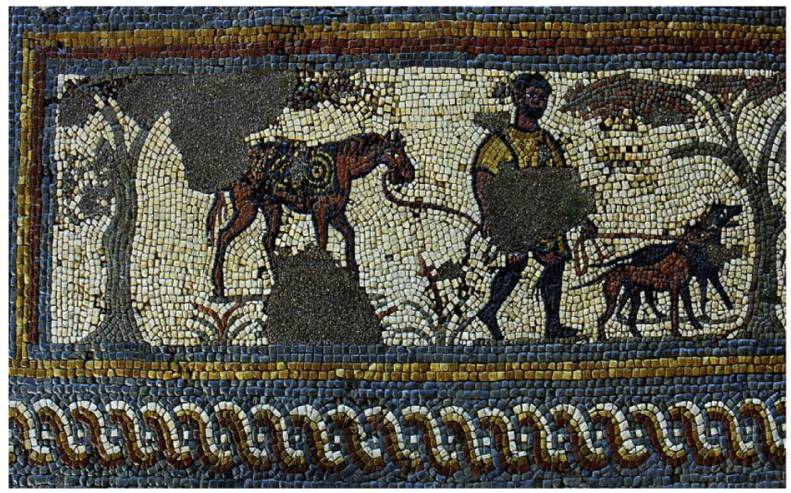

B)

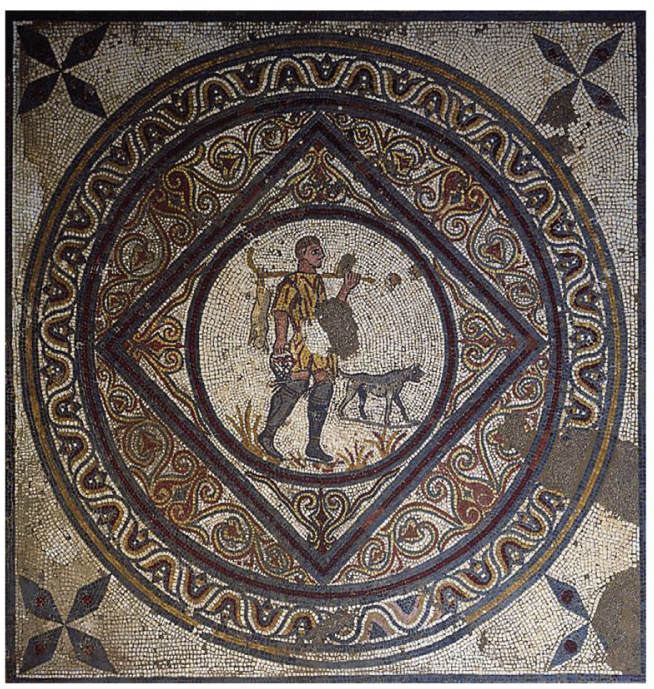

Fig. 1. Details of Roman mosaics from Conímbriga (Portugal) depicting dogs with different shape and colour: A) Two dogs on a leash with different coat colours, one brown and the other black (detail of mosaic $n^{\circ} 11$ of Casa dos Repuxos, (Oleiro, 1992), Photo by Humberto Rendeiro $\odot$ MMC/DGPC); B) A hunter carrying a hare and accompanied by a dog with a short snout (detail of mosaic $n^{\circ} 15$ of Casa dos Repuxos, (Oleiro 1992), Photo by Delfim Ferreira $\odot$ MMC/DGPC). (For interpretation of the references to colour in this figure legend, the reader is referred to the Web version of this article.)

Frantz et al., 2016; Leonard et al., 2002), especially in hot climates where DNA is poorly preserved. MtDNA sequence variability does not reflect directly variation in morphological traits, but regions such as the D-loop generally show a large degree of sequence variation between individuals, and it is most useful for addressing intraspecific evolutionary questions (e.g. Frantz et al., 2016; Leonard et al., 2002).

Worldwide mtDNA diversity of extant dogs indicate the existence of six clades or haplogroups: A, B, C, D, E and F (Savolainen et al., 2002). Clades A, B, C and D represent the majority of the maternal diversity found in dogs. Clade $A$ is the most frequent lineage currently observed in dogs from Europe (including Iberia) and North Africa, whereas clade D is the less represented and geographically restricted to Portugal, Spain, Morocco, Turkey and Scandinavia in present times (Ardalan et al., 2011; Pires et al., 2006; Savolainen et al., 2002). Extant dogs from Iberia and North Africa have high genetic diversity, carrying haplotypes belonging to clades A, B, C and D (Pires et al., 2006). Clades E and F were only detected in dogs from Asia. Concerning clade D in ancient European dogs, it was first detected in the Near East and later in South-eastern and Central Europe (Pionnier-Capitan, 2010) during the Neolithic ca. 10,000 BC. This clade would most likely have been introduced in 
Europe in the Neolithic along with other domesticated animals used for food, such as pig, sheep, goat and cattle (M. Ollivier, pers. com.).

In this study, we integrate osteometric, morphological and palaeogenetic data to characterize dog phenotypic and genetic variability of dogs of Roman times from Iberia and North Africa. Our hypothesis is that the greater morphological variation in dogs attributed to the Romans coincides with the presence of various dog mtDNA lineages. This would be in line with the Romans' interest in improving their domesticated animals - known to be more efficient and diverse, even extravagant.

\section{Material and methods}

\subsection{Zooarchaeological study}

The sites considered cover a time span from the Mesolithic ( $c a$. 7,500 years ago) to present day dogs and wolves in order to assess the diversity of dog sizes in each period including Roman, and how it compares with extant populations. We included measurements of the lower first molar tooth $\left(\mathrm{M}_{1}\right)$ length and the humerus distal breadth of dog specimens from 56 archaeological sites including 13 sites dated to the Roman period (Tables 1 and 2). We selected the $\mathrm{M}_{1}$ and distal humerus because these parts are frequently found in archaeological sites. $\mathrm{M}_{1}$ crown length and humerus distal breadth were measured following von den Driesch (1976).

Lengths of archaeological specimens of $\mathrm{M}_{1}$ were compared with measurements taken from Portuguese reference collections of skeletons of extant wolves ( $\mathrm{n}=45,19$ males, 18 females and 8 of unknown sex) and dogs $(\mathrm{n}=29$, unknown sex). These portuguese collections are held at Laboratório de Arqueociências, Direcção Geral do Património Cultural, Museu Nacional de História Natural e da Ciência and the Laboratório de Anatomia, Universidade Lusófona de Humanidades e Tecnologias, in Lisbon. In dogs, sexual dimorphism is present but it is not very strong (Cruz, 2007), and therefore this parameter does not affect size greatly. Adding to that, the variation of phenotypes and breeds also overlap any size variation derived from sexual dimorphism. Consequently, we did not consider sexual dimorphism as a variable in the analysis.

We measured the tooth and humerus from reference collections in Portugal and Spain and archaeological collections from Portugal. Measurements taken by other authors were used for comparisons (see Tables 1 and 2). The Coefficient of Variation (CV), being CV = (standard deviation/average) ${ }^{*} 100$, for the $\mathrm{M}_{1}$ length and humerus breadth was calculated for each period.

We used the non-parametric test of Siegel-Tukey (Siegel and Tukey, 1960) in order to test whether differences between the populations existed regarding the diversity of the measurements. This test measures the dispersion of values in two populations, that is, whether a population is more homogeneous than another.

\section{Genetic study}

\subsection{Archaeological sites}

The dog remains of this study derive from three archaeological sites located in the western range of the Roman Empire, namely (from south to north): Thamusida in northern Morocco (Mauretania Tingitana) in 1999; Monte Molião, in Lagos in southern Portugal (Lusitania) in 2006/2008; and Lugo in Galicia in northern Spain (Tarraconensis) in 2003. The exact location of these sites and the sampled materials are shown in Fig. 2. A description of the archaeological sites from where these samples were excavated is presented below. It should be noted that the archaeological remains of dog from Morocco and Spain are contemporaneous (3rd- 4th cent. AD - ca.1,600 years ago) whereas those from Portugal are older ( 1 st cent. BC-1st cent. AD - ca. 2,000 years ago).

Thamusida (Morocco) The ruins of the city, already known from the end of the 19th century AD, were systematically investigated in the course of the 1930s and 1960s. Archaeologists discovered the most ancient layers of Mauro settlement and the main Roman monuments. In the year $40 \mathrm{AD}$, the province of Mauretania Tingitana was founded by Rome; the ancient Mauro settlement was destroyed during military operations aimed at controlling the region. During the second half of the 1st century AD, a military camp, close to a ford on the Sebou River, was established there. Around this camp a new urban centre was born. This new small city included different facilities such as houses, baths, temples, taverns and shops. Walls were constructed during the second half of the 2 nd cent. AD. These were probably needed to resist attacks from the Berber tribes of the Gharb (west). It is also worth noting that at the end of the 3rd century AD the Roman army left the area, but the site continued to be inhabited. Later on, during the 7th-8th cent, Arabs arrived at this settlement, but they chose to live outside the ancient city walls.

Monte Molião (Lagos, Portugal) was a small Roman town located on the south coast of Portugal, which was built over an Iron Age oppidum. The Roman occupation began in the 2nd century BC (Republican period), with intensive connections to other Mediterranean areas including the Italian Peninsula, North Africa and Bay of Cadiz, and lasted until the end of the 2 nd century AD (Imperial period). Chronologies were obtained from the datable imported materials (ceramics) found on the site. Trading between Monte Molião and North Africa existed, namely with the area of presentday Tunisia during the Republican and the Imperial Roman periods, as attested through imported food products transported in amphorae (Arruda and Sousa, 2013) as well as the presence of abundant imported ceramics from this area (Arruda, 2007). Dog remains were found in layers related to the site's occupation, especially the Imperial period (1st -2nd century A.D.; Detry and Arruda, 2013).

Lugo (Lucus Augusti) (Spain) was a Roman city that developed during the Early Imperial period (late 1st century BC) in the northwestern region of the Iberian Peninsula. It eventually became Conventus Lucensis capital, one of the administrative units in which the Gallaecia province was divided (Rodríguez Colmenero, 2011). Excavations at the site Domus del Mitreo, revealed a diachronic occupation since the Roman period. Regarding the oldest records, they reflect a construction of the Early Imperial period, and a domus identified as a mitreo (for cult) was recorded (Alvar et al., 2006; Rodríguez and Cordeiro, 2014; Rodríguez Cao, 2006). This construction was renewed several times and it was damaged due to a Roman wall construction in the late 3rd cent. AD. It eventually disappeared at the end of 3rd cent. - 4th cent. AD during a refurbishment of the city. Dog remains excavated from deposition levels related to the renovation and destruction of the domus, can be dated to the 4th century, as indicated by other associated archaeological materials. The presence of camelids (possibly dromedary) among the faunal remains at Domus del Mitreo excavation site (C Fernandez-Rodriguez, pers. com.) may reflect connections with North Africa. There are also references to other parts of the Lugo city for the presence of North African products (Naveiro López, 1991) such as amphorae (Carreras Monfort, 2011; Naveiro López, 1991).

\subsection{Sub-sampling for aDNA analysis}

A total of 15 dog remains were sampled for ancient DNA (aDNA) analyses: one upper third pre-molar from Thamusida; two proximal femora and a mandible fragment from Monte Molião; and two 
Table 1

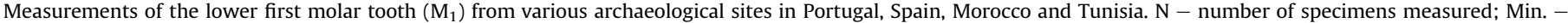
minimum value; Max. - maximum value; SD - Standard Deviation; CV - Coefficient of Variation (\%).

\begin{tabular}{|c|c|c|c|c|c|c|c|c|c|c|}
\hline Archaeological Site & Location & Country & $\begin{array}{l}\text { Roman } \\
\text { province }\end{array}$ & Chronology & $\mathrm{N}$ & Min. Max. & Average & SD & $\begin{array}{l}\text { CV } \\
(\%)\end{array}$ & References \\
\hline 20th Century Wolves & & Portugal & & & 45 & 23.830 .7 & 27.3 & 1.5 & 5.7 & (Detry and Cardoso, 2010) \\
\hline 20th Century Dogs & & $\begin{array}{l}\text { Portugal and } \\
\text { Spain }\end{array}$ & & & 29 & 14.625 .3 & 19.4 & 3.0 & 15.5 & C. Detry, personal communication \\
\hline Silos de Carnide & Lisboa & Portugal & & Modern Period & 8 & 17.920 .2 & 18.4 & 1.0 & 5.3 & $\begin{array}{l}\text { C. Detry and S.J.M. Davis, personal } \\
\text { communication }\end{array}$ \\
\hline $\begin{array}{l}\text { Mosteiro de Santo } \\
\text { André }\end{array}$ & Amares & Portugal & & Modern Period & 1 & 17.917 .9 & 0 & 0.0 & 0.0 & Davis, unpublished \\
\hline \multirow[t]{2}{*}{ Mosteiro do Bouro } & Amares & Portugal & & Modern Period & 2 & 19.722 .1 & 20.9 & 1.2 & 5.7 & Davis, unpublished \\
\hline & & & & Modern Period & 11 & 17.922 .1 & 18.8 & 1.4 & 7.4 & \\
\hline Lixeira & Silves & Portugal & & Medieval Islamic & 3 & 22.623 .1 & 22.8 & 0.2 & 1.0 & (Davis et al., 2008) \\
\hline \multirow[t]{2}{*}{ Alcáçova de Santarém } & Santarém & Portugal & & Medieval Islamic & 1 & 23.823 .8 & 0.0 & 0.0 & 0.0 & (Davis, 2006) \\
\hline & & & & Medieval Period & 4 & 22.623 .8 & 23.0 & 0.5 & 2.2 & \\
\hline Astorga & Astorga & Spain & Tarraconensis & $\begin{array}{l}\text { Late Roman (3rd-4th cent. } \\
\text { AD) }\end{array}$ & 14 & 16.123 .7 & 20.5 & 2.5 & 12.2 & (Fernandez-Rodriguez, 2000) \\
\hline Els Mallols & Barcelona & Spain & Tarraconensis & $\begin{array}{l}\text { Late Roman (3rd-4th cent. } \\
\text { AD) }\end{array}$ & 3 & 19.521 .0 & 20.2 & 0.6 & 3.1 & (Catagnano, 2016) \\
\hline Odrinhas & Sintra & Portugal & Lusitania & $\begin{array}{l}\text { Late Roman (3rd-4th cent. } \\
\text { AD) }\end{array}$ & 14 & 15.622 .0 & 19.0 & 2.0 & 10.5 & (Davis and Gonçalves, 2017) \\
\hline Monte Molião & Algarve & Portugal & Lusitania & $\begin{array}{l}\text { Imperial Roman (1st-2nd } \\
\text { cent. AD) }\end{array}$ & 1 & 17.517 .5 & 0.0 & 0.0 & 0.0 & (Detry and Arruda, 2013) \\
\hline Thamusida & & Morroco & $\begin{array}{l}\text { Mauretania } \\
\text { Tingitania }\end{array}$ & $\begin{array}{l}\text { Imperial Roman (1st-2nd } \\
\text { cent. AD) }\end{array}$ & 3 & 19.219 .9 & 19.6 & 0.3 & 1.5 & $\begin{array}{l}\text { (De Grossi Mazzorin and De Venuto, } \\
\text { 2010) }\end{array}$ \\
\hline Calle Almendralejo & Mérida & Spain & Lusitania & $\begin{array}{l}\text { Imperial Roman (1st-2nd } \\
\text { cent. AD) }\end{array}$ & 50 & 14.822 .7 & 19.2 & 1.8 & 9.6 & $\begin{array}{l}\text { C. Detry and F.J. Heras, personal } \\
\text { communication }\end{array}$ \\
\hline Alcáçova de Santarém & Santarém & Portugal & Lusitania & $\begin{array}{l}\text { Republican Roman (1st- } \\
\text { 2nd cent. BC) }\end{array}$ & 1 & 20.620 .6 & 0.0 & 0.0 & 0.0 & (Davis, 2006) \\
\hline \multirow[t]{2}{*}{ Odemira } & Odemira & Portugal & Lusitania & $\begin{array}{l}\text { Republican Roman (1st- } \\
\text { 2nd cent. BC) }\end{array}$ & 1 & 26.026 .0 & 0.0 & 0.0 & 0.0 & (Davis and Vilhena, 2017) \\
\hline & & & & Roman Period & 87 & 14.826 & 19.5 & 2.1 & 10.8 & \\
\hline Althiburos & & Tunisia & & Iron Age & 3 & 18.421 .7 & 20.5 & 1.5 & 7.3 & (Valenzuela-Lamas, 2016) \\
\hline R. dos Correeiros & Lisbon & Portugal & & Iron Age & 1 & 19.019 .0 & 0.0 & 0.0 & 0.0 & (Detry et al., 2016) \\
\hline Hereuet & Tarragona & Spain & & Iron Age & 3 & 22.423 .3 & 22.9 & 0.4 & 1.7 & $\begin{array}{l}\text { S. Valenzuela-Lamas, personal } \\
\text { communication }\end{array}$ \\
\hline Estinclells & Urgell & Spain & & Iron Age & 1 & 26.726 .7 & 0.0 & 0.0 & 0.0 & (Valenzuela-Lamas, 2010) \\
\hline Alorda Park & Barcelona & Spain & & Iron Age & 2 & 22.823 .0 & 22.9 & 0.0 & 0.0 & (Valenzuela-Lamas, 2008) \\
\hline Cerro Macareno & Sevilla & Spain & & Iron Age & 4 & 20.023 .0 & 21.4 & 1.4 & 6.5 & (Amberger, 1985) \\
\hline Cerro de la Tortuga & Malaga & Spain & & Iron Age & 1 & 22.022 .0 & 0.0 & 0.0 & 0.0 & (von den Driesch, 1973) \\
\hline Mas Castellar & Gerona & Spain & & Iron Age & 6 & 15.521 .6 & 19.6 & 2.0 & 10.2 & (Catagnano, 2016) \\
\hline \multirow[t]{2}{*}{ Los Toscanos } & Malaga & Spain & & Iron Age & 1 & 19.019 .0 & 0.0 & 0.0 & 0.0 & (von den Driesch, 1973) \\
\hline & & & & Iron Age & 22 & 15.526 .7 & 21.2 & 2.3 & 10.8 & \\
\hline Castelon Alto & Granada & Spain & & Bronze Age & 4 & 18.021 .0 & 19.9 & 1.1 & 5.7 & (Milz, 1986) \\
\hline Cerro de la Encina & Granada & Spain & & Bronze Age & 4 & 20.221 .3 & 20.7 & 0.5 & 2.4 & (Friesch, 1987) \\
\hline Terrena del Reloj & Granada & Spain & & Bronze Age & 3 & 18.520 .5 & 19.7 & 0.8 & 4.3 & (Milz, 1986) \\
\hline Fuente Álamo & Almeria & Spain & & Bronze Age & 3 & 19.521 .5 & 20.3 & 0.8 & 4.2 & (von den Driesch et al., 1985) \\
\hline Purullena & Granada & Spain & & Bronze Age & 8 & 17.223 .0 & 20.5 & 1.8 & 8.5 & (Lauk, 1976) \\
\hline Monachil & Granada & Spain & & Bronze Age & 2 & 20.521 .7 & 21.1 & 0.6 & 2.8 & (Lauk, 1976) \\
\hline Cabezo Redondo & Alicante & Spain & & Bronze Age & 5 & 16.520 .8 & 18.7 & 1.5 & 7.8 & (Boessneck et al., 1969) \\
\hline Sacaojos Bei la Baneza & Léon & Spain & & Bronze Age & 3 & 22.523 .5 & 23.0 & 0.4 & 1.8 & $\begin{array}{l}\text { (Boessneck and von den Driesch, } \\
\text { 1980) }\end{array}$ \\
\hline Los Palacios & Ciudad Real & Spain & & Bronze Age & 2 & 19.521 .0 & 20.3 & 0.8 & 3.7 & $\begin{array}{l}\text { (Boessneck and von den Driesch, } \\
\text { 1980) }\end{array}$ \\
\hline Azuer & Ciudad Real & Spain & & Bronze Age & 5 & 17.521 .5 & 20.4 & 1.5 & 7.2 & $\begin{array}{l}\text { (Boessneck and von den Driesch, } \\
\text { 1980) }\end{array}$ \\
\hline \multirow[t]{2}{*}{ Lloma de Baxi } & & Spain & & Bronze Age & 2 & 19.723 .0 & 21.4 & 1.7 & 7.7 & (Sanchis and Sarrión, 2004) \\
\hline & & & & Bronze Age & 41 & 16.523 .5 & 20.4 & 1.6 & 7.8 & \\
\hline Leceia & Oeiras & Portugal & & Chalcolithic & 2 & 19.020 .0 & 19.5 & 0.4 & 1.9 & (Pires et al., 2001) \\
\hline Zambujal & Torres Vedras & Portugal & & Chalcolithic & 5 & 17.723 .0 & 20.6 & 0.0 & 0.0 & $\begin{array}{l}\text { (von den Driesch and Boessneck, } \\
\text { 1976) }\end{array}$ \\
\hline P. Torrão & Alentejo & Portugal & & Chalcolithic & 2 & 20.320 .6 & 20.5 & 0.2 & 0.7 & Davis, unpublished \\
\hline Paraíso & Alentejo & Portugal & & Chalcolithic & 2 & 21.022 .0 & 21.5 & 0.5 & 2.3 & Davis, unpublished \\
\hline Camino de las Yeseras & Madrid & Spain & & Chalcolithic & 12 & 18.122 .2 & 20.2 & 1.4 & 6.7 & (Daza, 2015) \\
\hline Cerro de la Virgen & Granada & Spain & & Chalcolithic & 5 & 18.221 .0 & 19.9 & 0.0 & 0.0 & (von den Driesch, 1972) \\
\hline Marizulo & Guipuzcoa & Spain & & Chalcolithic & 1 & 21.421 .4 & 0.0 & 0.0 & 0.0 & (Altuna, 1967) \\
\hline \multirow[t]{2}{*}{ Camino del Molino } & Murcia & Spain & & Chalcolithic & 56 & 17.221 .8 & 20.0 & 1.0 & 5.0 & (Catagnano, 2016) \\
\hline & & & & Chalcolithic & 83 & 17.223 & 20.1 & 1.1 & 5.5 & \\
\hline SJA Portam Latinam & Bilbao & Spain & & Neolithic & 1 & 18.018 .0 & 0.0 & 0.0 & 0.0 & (Altuna and Mariezkurrena, 2007) \\
\hline Cova de L'Or & Alacant & Spain & & Neolithic & 1 & 20.020 .0 & 0.0 & 0.0 & 0.0 & (Sanchis and Sarrión, 2004) \\
\hline Sierra del Mas Bonet & Gerona & Spain & & Neolithic & 1 & 21.021 .0 & 0.0 & 0.0 & 0.0 & (Catagnano, 2016) \\
\hline Lameiras & Sintra & Portugal & & Neolithic & 1 & 20.720 .7 & 0.0 & 0.0 & 0.0 & $\begin{array}{l}\text { S.J.M. Davis personal } \\
\text { communication }\end{array}$ \\
\hline \multirow[t]{2}{*}{ Belas } & Sintra & Portugal & & Neolithic & 1 & 20.020 .0 & 0.0 & 0.0 & 0.0 & Davis, unpublished \\
\hline & & & & Neolithic & 5 & 18.021 .0 & 19.9 & 1.0 & 5.0 & \\
\hline
\end{tabular}


Table 1 (continued)

\begin{tabular}{|c|c|c|c|c|c|c|c|c|c|c|}
\hline Archaeological Site & Location & Country & $\begin{array}{l}\text { Roman } \\
\text { province }\end{array}$ & Chronology & $\mathrm{N}$ & Min. Max. & Average & SD & $\begin{array}{l}\mathrm{CV} \\
(\%)\end{array}$ & References \\
\hline $\begin{array}{l}\text { Muge (C. Arruda \& C. } \\
\text { Amoreira) }\end{array}$ & $\begin{array}{l}\text { Salvaterra de } \\
\text { Magos }\end{array}$ & Portugal & & Mesolithic & 2 & 20.521 .6 & 21.1 & 0.6 & 2.6 & (Detry and Cardoso, 2010) \\
\hline \multirow[t]{2}{*}{$\begin{array}{l}\text { Sado (Poças de São } \\
\text { Bento) }\end{array}$} & Alcácer do Sal & Portugal & & Mesolithic & 1 & 21.721 .7 & 0.0 & 0.0 & 0.0 & $\begin{array}{l}\text { C. Detry and S.J.M. Davis, personal } \\
\text { communication }\end{array}$ \\
\hline & & & & Mesolithic & 3 & 20.521 .7 & 21.3 & 0.5 & 2.6 & \\
\hline
\end{tabular}

tibiae, four humeri, two radii, one scapula, one pelvis and one femur from Lugo. These specimens were labelled and stored in individual zip-lock plastic bags and kept separately from modern samples.

We followed specific protocols for sub-sampling and aDNA extraction and took adequate precautions to avoid contamination: sub-sampling of archaeological remains was performed in the aDNA dedicated facilities at PALGENE, French National Platform of Palaeogenetics at the École Normale Supérieure de Lyon (France) and the Archaeological Research Laboratory of Stockholm University (Sweden). After ultra-violet sterilization of the outermost surfaces and removal of an approximately $1 \mathrm{~mm}$ layer from the surface, some powder of bone/tooth was collected from each sample using a sterile scalpel or a Dremel tool. Replicas were kept in a freezer at $-20^{\circ} \mathrm{C}$ for subsequent analyses.

\subsection{Isolation of aDNA}

Bone or tooth powder (100-200 mg) was digested overnight with $1 \mathrm{~mL}$ of buffer EDTA (ethylene diamine tetra acetic acid, $\mathrm{pH} 8$ ) $0.5 \mathrm{M}$ and Urea $1 \mathrm{M}$ with $10 \mu \mathrm{L}$ of proteinase $\mathrm{K}(20 \mathrm{mg} / \mathrm{mL}$ in water $)$ at $38{ }^{\circ} \mathrm{C}$ with constant agitation. For each sample, the lysate volume was concentrated down to $100 \mu \mathrm{l}$ with Amicon columns (MilliporeAmicon Ultra-4 $30 \mathrm{k} \mathrm{Da}$ ) through centrifugation at $4,000 \mathrm{~g}$ for 10-15 min. The sample volume was then mixed with $5 \times$ PB buffer from the commercial kit QIAquick PCR Purification Kit from Qiagen. Ancient DNA was recovered, following the manufacturer's protocol, in a final volume of $100 \mu \mathrm{L}$. Two negative extraction controls were included in every batch of six samples. Duplicates of aDNA extracts were obtained independently from each specimen.

\subsection{Mitochondrial DNA amplification}

We analysed a $D$-loop fragment of 181 base pairs (bp). In extant dogs, this region is amplified by Polymerase chain reaction (PCR) with DL1-DL2 primers (Leonard et al., 2002), and recovers the majority of the mtDNA haplotypic variability included in the most frequent dog haplogroups (i.e., Hgs A, B, C and D). These primers were also useful in ancient samples of dogs and wolves. We used primer pairs DL1/DL3 and DL7/DL2 (Table 3) in two separate PCR reactions to amplify the mtDNA region between positions 15,495 and 15,676 in the dog reference sequence (EU789784). After amplification, these two fragments of 187 and 108 bp, respectively, superimpose for an extension of 94 nucleotides.

PCR mixtures contained $2 \mu \mathrm{L}$ of genomic DNA, $1 \times$ Taq polymerase buffer (Applied Biosystem), $2.5 \mathrm{mM}$ of $\mathrm{MgCl}_{2}$ (Applied Biosystem), $0.25 \mathrm{mM}$ of each deoxynucleoside triphosphate (dNTP) (Sigma), $0.02 \mathrm{mg}$ Bovine Serum Albumin (Roche), $0.5 \mu \mathrm{M}$ of each PCR primer, $2.5 \mathrm{U}$ of Hot start Taq DNA polymerase (Applied Biosystem) and PCR water (Qiagen) in a total of a $25 \mu \mathrm{L}$ PCR reaction. In all amplification reactions, the primer sequences included multiplex identifiers for libraries (MIDs), i.e., 10 nucleotide sequence tags that allow for multiplexing in emulsion PCR during 454-sequencing (Roche). To monitor for possible aerosol contaminations, a specific control was included in every PCR assay, which were limited to eight aDNA extracts. The aerosol control was a single tube that was kept opened during the PCR set up. We also monitored possible contaminations from reagents by setting up a negative control with water as a replacement to DNA extract (PCR-mix control). Negative controls were systematically used, and all extraction blanks were also subject to PCR amplification.

Amplification reactions were performed in an Applied Biosystems thermal cycler (Veriti), with an initial denaturation step of $94{ }^{\circ} \mathrm{C}$ for $10 \mathrm{~min}$; followed by 55 cycles of denaturation at $94{ }^{\circ} \mathrm{C}$ (30 s), annealing at $52{ }^{\circ} \mathrm{C}$ (30 s for DL1/DL3 primer pair) or $48^{\circ} \mathrm{C}$ for (30 s for DL7/DL2 primer pair), and extension at $72{ }^{\circ} \mathrm{C}(45 \mathrm{~s})$; followed by a final extension step at $72{ }^{\circ} \mathrm{C}$ for $10 \mathrm{~min}$.

Amplifications were verified by the electrophoresis of $5 \mu \mathrm{L}$ of each PCR product in $2 \%$ ethidium bromide agarose gels in Tris/ Borate/EDTA (TBE) $(0.5 \times)$ buffer. Electrophoresis ran at $10 \mathrm{~V} / \mathrm{cm}$ for $30 \mathrm{~min}$. Samples that provided positive signal at the expected size were sequenced. Negative controls remained blank through agarose gel inspection.

For DNA sequencing, $20 \mu \mathrm{L}$ of the remaining PCR product were electrophoresed in a second $2 \%$ agarose gel and the amplified DNA excised from the gel with a sterile scalpel under UV light. The PCR products were purified using the QIAquick Gel Extraction Kit (Qiagen) and eluted in $30 \mu \mathrm{L}$ elution solution. If primer dimer was present, we used the MinElute PCR Purification Kit (Qiagen) following the manufacturer's protocol.

\subsection{Mitochondrial DNA sequencing}

We used the Quant-iTrm dsDNA High-Sensitivity Assay Kit (Invitrogen) to quantify the purified positive PCR products. Equimolar mixtures of pooled amplification products were sequenced using the 454-GS Junior technology (Roche) in accordance to the manufacturer's protocols. Sequence reads were identified through primers and MIDs and aligned against reference NCBI sequences. The GALAXY platform (http://galaxy.psu.edu/), a web-based genome analysis tool (Afgan et al., 2016) was used to obtain the sequence files for each pooled PCR product. Dog sequences were compared with the DNA sequence information stored in the GenBank database. This was done using the "basic local alignment search tool" (BLAST) program (http://blast.ncbi.nlm.nih.gov) (Altschul et al., 1990) and the blastn algorithm.

For multiple alignments, the Seaview software (Galtier et al., 1996) was used and $60 \%$ consensus sequences were generated for each individual from independent amplifications (see sequencing coverage for each dog specimen in Table 4). If any conflict persisted preventing haplogroup assignment the specimen was sequenced until resolution. Partial mtDNA sequences of ancient Canis remains were deposited in GenBank (accession numbers KY014672-KY014674; KY014684-KY014894 and KY464999) (Table 4).

\subsection{Phylogenetic analyses}

Relationships between haplotypes were investigated using NETWORK v5.0.0.0 (Fluxus Technology Ltd, 2004-2016) software 
Table 2

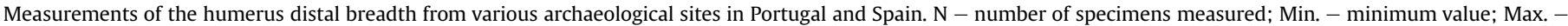
maximum value; SD - Standard Deviation; CV - Coefficient of Variation (\%).

\begin{tabular}{|c|c|c|c|c|c|c|c|c|c|c|c|}
\hline $\begin{array}{l}\text { Archaeological } \\
\text { Site }\end{array}$ & Location & Country & $\begin{array}{l}\text { Roman } \\
\text { province }\end{array}$ & Chronology & $\mathrm{N}$ & Min. & Max. & Average & SD & $\begin{array}{l}\text { CV } \\
(\%)\end{array}$ & References \\
\hline $\begin{array}{l}\text { 20th Century } \\
\text { Wolves }\end{array}$ & & Portugal & & & 30 & 32.4 & 48.9 & 41.8 & 4.2 & 10.0 & (Detry and Cardoso, 2010) \\
\hline $\begin{array}{l}\text { 20th Century } \\
\text { Dogs }\end{array}$ & & Portugal\&Spain & & & 25 & 19.3 & 47.5 & 29.3 & 7.7 & 26.3 & C. Detry, personal communication \\
\hline Silos de Carnide & Lisboa & Portugal & & Modern period & 8 & 20.9 & 28.6 & 24.7 & 3 & 12.1 & $\begin{array}{l}\text { C. Detry and S.J.M. Davis, personal } \\
\text { communication }\end{array}$ \\
\hline \multirow{2}{*}{$\begin{array}{l}\text { Alcáçova de } \\
\text { Santarém }\end{array}$} & Santarém & Portugal & & Modern period & 1 & 22.3 & 22.3 & 0.0 & 0.0 & 0.0 & (Davis, 2006) \\
\hline & & & & Modern period & 9 & 20.9 & 28.6 & 24.4 & 3 & 12.3 & \\
\hline $\begin{array}{l}\text { Alcáçova de } \\
\text { Santarém }\end{array}$ & Santarém & Portugal & & Christian period & 1 & 36.6 & 36.6 & 0.0 & 0.0 & 0.0 & (Davis, 2006) \\
\hline \multirow{2}{*}{$\begin{array}{l}\text { Alcáçova de } \\
\text { Santarém }\end{array}$} & Santarém & Portugal & & Islamic period & 1 & 27.2 & 27.2 & 0.0 & 0.0 & 0.0 & (Davis, 2006) \\
\hline & & & & Medieval period & 2 & 27.2 & 36.6 & 31.7 & 4.5 & 14.2 & \\
\hline Els Mallols & Barcelona & Spain & Tarraconensis & $\begin{array}{l}\text { Late Roman (3rd-4th cent. } \\
\text { AD) }\end{array}$ & 3 & 26.1 & 38.7 & 33.1 & 5.3 & 16.0 & (Catagnano, 2016) \\
\hline Odrinhas & Sintra & Portugal & Lusitania & $\begin{array}{l}\text { Late Roman (3rd-4th cent. } \\
\text { AD) }\end{array}$ & 10 & 20.1 & 31.6 & 26.4 & 3.7 & 14.0 & (Davis and Gonçalves, 2017) \\
\hline Astorga & Léon & Spain & Tarraconensis & $\begin{array}{l}\text { Late Roman (3rd-4th cent. } \\
\text { AD) }\end{array}$ & 19 & 23.7 & 39.5 & 29.6 & 4.8 & 16.2 & (Fernandez-Rodriguez, 2000) \\
\hline Vila Madrid & Madrid & Spain & Lusitania & $\begin{array}{l}\text { Imperial Roman (1st-2nd } \\
\text { cent. } A D)\end{array}$ & 17 & 21.3 & 38.4 & 31.3 & 4.9 & 15.7 & (Colominas, 2009) \\
\hline Baetulo & Barcelona & Spain & Lusitania & $\begin{array}{l}\text { Imperial Roman (1st-2nd } \\
\text { cent. AD) }\end{array}$ & 1 & 26.2 & 26.2 & 0.0 & 0.0 & 0.0 & (Colominas, 2009) \\
\hline Munigua & Sevilla & Spain & Baetica & $\begin{array}{l}\text { Imperial Roman (1st-2nd } \\
\text { cent. AD) }\end{array}$ & 1 & 20.0 & 20.0 & 0.0 & 0.0 & 0.0 & (Boessneck and von den Driesch, 1980) \\
\hline $\begin{array}{l}\text { Calle } \\
\text { Almendralejo }\end{array}$ & Mérida & Spain & Lusitania & $\begin{array}{l}\text { Imperial Roman (1st-2nd } \\
\text { cent. AD) }\end{array}$ & 24 & 20.1 & 31.6 & 26.4 & 3.7 & 14.0 & $\begin{array}{l}\text { C. Detry and F.J. Heras, personal } \\
\text { communication }\end{array}$ \\
\hline Lugo & Galiza & Spain & Tarraconensis & $\begin{array}{l}\text { Imperial Roman (1st-2nd } \\
\text { cent. AD) }\end{array}$ & 2 & 25.6 & 32.4 & 29.0 & 3.4 & 11.7 & (Fernandez-Rodriguez, 2000) \\
\hline \multirow[t]{2}{*}{$\begin{array}{l}\text { Mesas de } \\
\text { Castelinho }\end{array}$} & Almodôvar & Portugal & Lusitania & $\begin{array}{l}\text { Republican Roman (1st-2nd } \\
\text { cent. BC) }\end{array}$ & 1 & 22.7 & 22.7 & 0.0 & 0.0 & 0.0 & (Valenzuela-Lamas and Fabião, 2012) \\
\hline & & & & Roman period & 79 & 20.0 & 40.9 & 29.9 & 5.3 & 17.7 & \\
\hline $\begin{array}{c}\text { Cerro de la } \\
\text { Tortuga }\end{array}$ & Malaga & Spain & & Iron Age & 1 & 26.2 & 26.2 & 0.0 & 0.0 & 0.0 & (von den Driesch, 1973) \\
\hline Can Xercanvins & Barcelona & Spain & & Iron Age & 1 & 34.1 & 34.1 & 0.0 & 0.0 & 0.0 & (Catagnano, 2016) \\
\hline Mas Castellar & Gerona & Spain & & Iron Age & 5 & 23.6 & 33.3 & 28.5 & 3.3 & 11.6 & (Catagnano, 2016) \\
\hline \multirow{2}{*}{$\begin{array}{l}\text { Rua dos } \\
\quad \text { Correeiros }\end{array}$} & Lisbon & Portugal & & Iron Age & 1 & 25.4 & 25.4 & 0.0 & 0.0 & 0.0 & (Detry et al., 2016) \\
\hline & & & & Iron Age & 8 & 23.6 & 34.1 & 28.5 & 3.5 & 12.3 & \\
\hline Cabezo Redondo & Alicante & Spain & & Bronze Age & 7 & 24.3 & 30.6 & 27.2 & 1.9 & 7.0 & (Boessneck et al., 1969) \\
\hline Monachil & Granada & Spain & & Bronze Age (Argaric) & 4 & 26.5 & 31.7 & 28.6 & 2.0 & 7.0 & (Lauk, 1976) \\
\hline Purullena & Granada & Spain & & Bronze Age & 10 & 22.0 & 31.0 & 26.6 & 2.9 & 10.9 & (Lauk, 1976) \\
\hline Fuente Álamo & Almeria & Spain & & Bronze Age & 7 & 26.0 & 31.0 & 27.9 & 1.7 & 6.1 & (von den Driesch et al., 1985) \\
\hline Terrena del Reloj & Granada & Spain & & Bronze Age (Argaric) & 2 & 23.5 & 29.0 & 26.3 & 2.8 & 10.6 & (Milz, 1986) \\
\hline $\begin{array}{l}\text { Muntanya } \\
\text { Assolada }\end{array}$ & Valência & Spain & & Bronze Age & 1 & 25.8 & 25.8 & 0.0 & 0.0 & 0.0 & (von den Driesch, 1973) \\
\hline Azuer & Ciudad Real & Spain & & Bronze Age & 1 & 33.5 & 33.5 & 0.0 & 0.0 & 0.0 & (Boessneck and von den Driesch, 1980) \\
\hline Can Roqueta & Sabadell & Spain & & Bronze Age & 9 & 25.0 & 33.0 & 28.3 & 0.0 & 0.0 & (Albizuri, 2011) \\
\hline \multirow[t]{2}{*}{$\begin{array}{l}\text { Cerro de la } \\
\text { Encina }\end{array}$} & Granada & Spain & & Bronze Age & 5 & 25.9 & 33.2 & 29.0 & 2.5 & 8.6 & (Friesch, 1987) \\
\hline & & & & Bronze Age & 46 & 22.0 & 33.5 & 27.8 & 2.6 & 9.4 & \\
\hline Zambujal & Torres Novas & Portugal & & Chalcolithic & 1 & 26.0 & 26.0 & 0.0 & 0.0 & 0.0 & (von den Driesch and Boessneck, 1976) \\
\hline Leceia & Oeiras & Portugal & & Chalcolithic & 3 & 26.0 & 29.0 & 27.5 & 1.2 & 4.4 & (Pires et al., 2001) \\
\hline $\begin{array}{l}\text { Cerro de la } \\
\text { Virgen }\end{array}$ & Granada & Spain & & Chalcolithic & 6 & 24.8 & 30.2 & 27.6 & 1.6 & 5.8 & (von den Driesch, 1972) \\
\hline Les Jovades & Alacant & Spain & & Chalcolithic & 1 & 25.8 & 25.8 & 25.8 & 0.0 & 0.0 & (Sanchis and Sarrión, 2004) \\
\hline Marizulo & Guipuzcoa & Spain & & Chalcolithic & 1 & 33.8 & 33.8 & 33.8 & 0.0 & 0.0 & (Altuna, 1967) \\
\hline $\begin{array}{l}\text { Camino del } \\
\text { Molino }\end{array}$ & Murcia & Spain & & Chalcolithic & 40 & 24.4 & 38.9 & 28.2 & 3.0 & 10.6 & (Catagnano, 2016) \\
\hline \multirow[t]{2}{*}{$\begin{array}{l}\text { Camino de las } \\
\text { Yeseras }\end{array}$} & Madrid & Spain & & Chalcolithic & 3 & 28.5 & 31.5 & 30.0 & 1.2 & 4.0 & (Daza, 2015) \\
\hline & & & & Chalcolithic & 55 & 24.4 & 38.9 & 28.2 & 2.8 & 9.9 & \\
\hline Muge & $\begin{array}{l}\text { Salvaterra de } \\
\text { Magos }\end{array}$ & Portugal & & Mesolithic & 1 & 23.5 & 23.5 & 23.5 & $\mathbf{0 . 0}$ & 0.0 & (Detry and Cardoso, 2010) \\
\hline
\end{tabular}

to construct a Median-Joining (MJ) network (Bandelt et al., 1999). Nucleotide (nt) substitutions weighted 10 for transitions and 30 for transversions so that the component with the lowest expected mutation rate was assigned the highest weight (Bandelt et al.,
2000). The identification of dog clades was undertaken through comparison with reference sequence data of extant Iberian dogs and wolves trimmed to the 181 base pairs fragment.

Identification of dog clades was done by comparison with 
A)

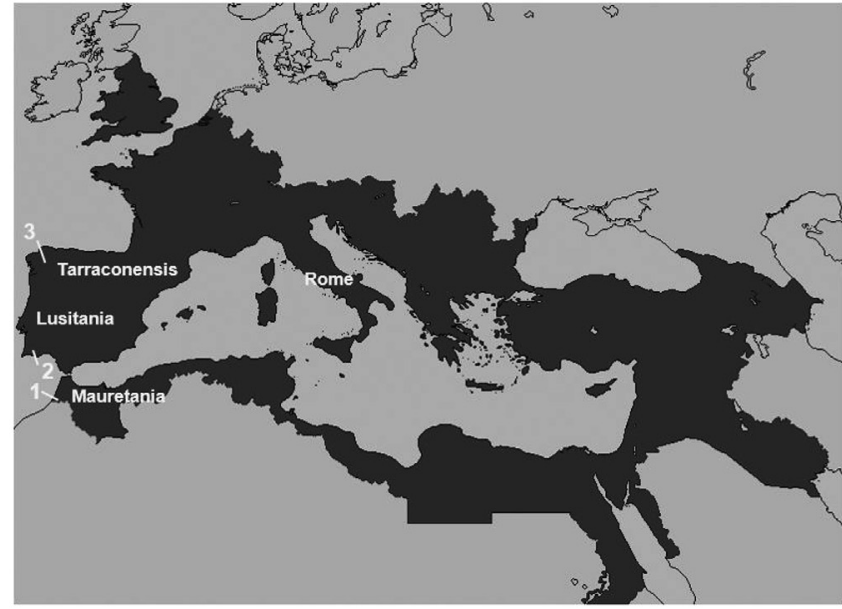

B)
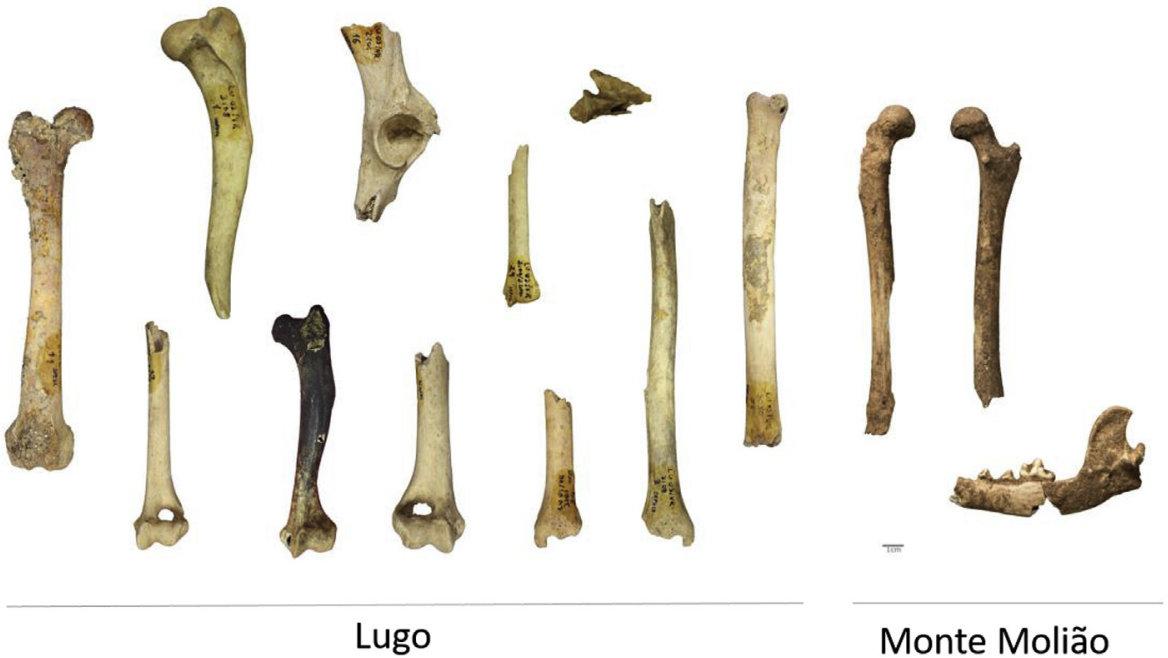

Monte Molião

Fig. 2. A) Location of the archaeological sites from where the $15 \mathrm{dog}$ remains used in the genetic analysis were recovered. The sampling was carried out in the western-most range of the Roman Empire, namely (from south to north): 1 - Thamusida, Morocco (Mauretania Tingitana); $\mathbf{2}$ - Monte Molião, Portugal (Lusitania); 3 - Lugo, Spain (Tarraconensis). Shaded in black is the maximum extent of the Roman empire. B) Sampled materials from Lugo and Monte Molião. Note: The sample from Thamusida was fragmented after sub-sampling for DNA analysis and no picture was taken. Photos by Carlos Fernandez-Rodriguez (material from Lugo) and José Paulo Ruas (material from Monte Molião).

Table 3

Primer sequences for mtDNA-control region amplification in Canis.

\begin{tabular}{ll}
\hline Primer Name & Primer Sequence $5^{\prime}-3^{\prime}$ \\
\hline DL1F forward & GTG CTA TGT CAG TAT CTC CAG G \\
DL3R reverse & CCC TTA TTG GAC TAA GTG ATA TGC AT \\
DL7F forward & TAT TAT ATC CTT ACA TAG GAC \\
DL2R reverse & GCA AGG GTT GAT GGT TTC TCG \\
\hline
\end{tabular}

reference sequence data on extant dogs from Iberia and North Africa, and comprising breed and village dogs from 1) Pires et al. (2006), 49 haplotypes, 887 base pair long with GenBank accession numbers AY706476-AY706524 (Pires et al., 2006); and 2) Pang et al. (2009), haplotypes A4, A5, A10, A11, A19, A20, A22, A33, A34, A127, B1, D6, D7 (Pang et al., 2009).

An alignment of all these sequences/haplotypes is available from Partial_MtDNA_SequenceAlignment_DOG_Roman_QInt (fasta).

Short mtDNA fragments may not exactly reflect the phylogeny as determined by complete mitogenomes. We thus constructed a Bayesian phylogenetic tree to confirm haplogroup assignment of the partial mtDNA sequences obtained in this study by comparison with well-defined dog matrilines from GenBank. The software MrBayes (Huelsenbeck et al., 2001; Ronquist and Huelsenbeck, 2003) was used with the evolutionary model GTR + I + gamma. The shape parameter of the gamma distribution was 0.7424 and the proportion of invariable sites (I) was 0.6851 . We used $10,000,000$ generations, sampling every 1,000 th generation, and default settings for the remaining options. Convergence of the Monte Carlo Markov Chain and burn-in were determined through the analysis of the generations versus the log probability plot using the trace analysis tool TRACER v1.6. (Rambaut et al., 2014). The initial burn-in step discarded $20 \%$ of the samples. This allowed for haplogroup assignment of all our Roman dog partial mtDNA sequences with high confidence.

\section{Results}

\subsection{Zooarchaeological analyses}

Tables 1 and 2 and the associated histograms (Figs. 3 and 4) 
Table 4

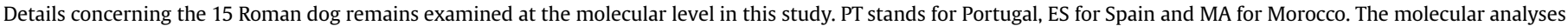
were performed in two independent laboratories: AFL in Stockholm, Sweden and ENS in Lyon, France.

\begin{tabular}{|c|c|c|c|c|c|c|c|c|}
\hline Sample & $\begin{array}{l}\text { Archaeological site, } \\
\text { Country }\end{array}$ & Chronology & $\begin{array}{l}\text { Skeletal element } \\
\text { recovered }\end{array}$ & aDNA Laboratory & $\begin{array}{l}\text { mtDNA sequence } \\
\text { (base pairs) }\end{array}$ & $\begin{array}{l}454 \text { sequencing } \\
\text { coverage }\end{array}$ & $\begin{array}{l}\text { GenBank Accession } \\
\text { number }\end{array}$ & $\begin{array}{l}\text { mtDNA } \\
\text { Haplogroup (Hg) }\end{array}$ \\
\hline SEP013 & Lugo, ES & $\begin{array}{l}\text { 3rd - 4th } \\
\text { cent. AD }\end{array}$ & tibia & $\begin{array}{l}\text { AFL, Stockholm } \\
\text { University, Sweden }\end{array}$ & 139 & 559 & KY014684 & A \\
\hline SEP014 & Lugo, ES & $\begin{array}{l}\text { 3rd - 4th } \\
\text { cent. AD }\end{array}$ & humerus & $\begin{array}{l}\text { AFL, Stockholm } \\
\text { University, Sweden }\end{array}$ & 139 & 155 & KY014685 & A \\
\hline SEP015 & Lugo, ES & $\begin{array}{l}\text { 3rd - 4th } \\
\text { cent. AD }\end{array}$ & radius & $\begin{array}{l}\text { AFL, Stockholm } \\
\text { University, Sweden }\end{array}$ & 139 & 42 & KY014686 & A \\
\hline SEP016 & Lugo, ES & $\begin{array}{l}\text { 3rd - 4th } \\
\text { cent. AD }\end{array}$ & scapula & $\begin{array}{l}\text { AFL, Stockholm } \\
\text { University, Sweden }\end{array}$ & 139 & 83 & KY014687 & A \\
\hline SEP017 & Lugo, ES & $\begin{array}{l}\text { 3rd - 4th } \\
\text { cent. AD }\end{array}$ & pelvis & $\begin{array}{l}\text { AFL, Stockholm } \\
\text { University, Sweden }\end{array}$ & 139 & 48 & KY014688 & A \\
\hline SEP018 & Lugo, ES & $\begin{array}{l}\text { 3rd - 4th } \\
\text { cent. AD }\end{array}$ & humerus & $\begin{array}{l}\text { AFL, Stockholm } \\
\text { University, Sweden }\end{array}$ & 139 & 29 & KY014689 & A \\
\hline SEP019 & Lugo, ES & $\begin{array}{l}\text { 3rd - 4th } \\
\text { cent. AD }\end{array}$ & humerus & $\begin{array}{l}\text { AFL, Stockholm } \\
\text { University, Sweden }\end{array}$ & 139 & 50 & KY014690 & A \\
\hline SEP020 & Lugo, ES & $\begin{array}{l}\text { 3rd - 4th } \\
\text { cent. AD }\end{array}$ & radius & $\begin{array}{l}\text { AFL, Stockholm } \\
\text { University, Sweden }\end{array}$ & 139 & 38 & KY014691 & $\mathrm{D}$ \\
\hline SEP021 & Lugo, ES & $\begin{array}{l}\text { 3rd - 4th } \\
\text { cent. AD }\end{array}$ & tibia & $\begin{array}{l}\text { AFL, Stockholm } \\
\text { University, Sweden }\end{array}$ & 139 & 135 & KY014692 & A \\
\hline SEP022 & Lugo, ES & $\begin{array}{l}\text { 3rd - 4th } \\
\text { cent. AD }\end{array}$ & femur & $\begin{array}{l}\text { AFL, Stockholm } \\
\text { University, Sweden }\end{array}$ & 139 & 126 & KY014693 & $\mathrm{D}$ \\
\hline SEP023 & Lugo, ES & $\begin{array}{l}\text { 3rd - 4th } \\
\text { cent. AD }\end{array}$ & humerus & $\begin{array}{l}\text { AFL, Stockholm } \\
\text { University, Sweden }\end{array}$ & 139 & 23 & KY014694 & $\mathrm{D}$ \\
\hline LYEP57 & Thamusida, MA & 1st cent. AD & $\begin{array}{l}\text { tooth - lower third } \\
\text { pre-molar }\end{array}$ & ENS-Lyon, France & 109 & 225 & KY464999 & A \\
\hline LYEP59 & Monte Molião, PT & 1st cent. BC & proximal femur & ENS-Lyon, France & 181 & 746 & KY014672 & A \\
\hline LYEP60 & Monte Molião, PT & 1st cent. AD & mandible fragment & ENS-Lyon, France & 166 & 110 & KY014673 & A \\
\hline LYEP61 & Monte Molião, PT & 1st cent. BC & proximal femur & ENS-Lyon & 181 & 479 & KY014674 & A \\
\hline
\end{tabular}

summarize information for each archaeological site and its period. Data from the Roman and Late Roman periods-eight archaeological sites for the $M_{1}$ length measurements and nine for the humerus distal breadth-confirm the wide variability in size for dogs at that time.

Among the 15 Canis specimens from the Roman period selected for aDNA analyses, only three were possible to measure and their measurements fall within the range of $\mathrm{M}_{1}$ length (one sample, Monte Molião) and humerus distal breadth (two samples, Lugo) for dogs rather than for wolves. Besides this metrical criterion, all archaeological information from where these canid elements were found corresponds to domestic contexts, thus reinforcing their identification as the domestic subspecies.

The results suggest that Chalcolithic and Bronze Age dogs are significantly more uniform than Roman and present-day ones. The low number of measurements for the Iron Age and Modern times prevents us from knowing whether these dog populations were either diverse or homogeneous.

As for cranial variability, the $\mathrm{CV}$ calculated for the Roman period (eight distinct archaeological sites) indicates that $\mathrm{M}_{1}$ length variability in Roman time is larger $(\mathrm{CV}=10.8 \%)$ compared to other periods $(1-7.4 \%)$, the same as in Iron Age $(C V=10.8 \%)$, but lower when compared to extant dogs $(C V=15.5 \%)$ (Table 1$)$. The humerus distal breadth measurements show similar results: the CV calculated from the combined values of nine different archaeological sites show its highest value in the Roman period $(\mathrm{CV}=17.7 \%)$ followed by extant dogs $(\mathrm{CV}=26.3 \%)$. For this measurement, the $\mathrm{CV}$ value for the Iron Age is much lower $(\mathrm{CV}=12.3 \%)$.

The stacked histograms (Figs. 3 and 4) also show that the amplitude of values seems higher in the Roman period with smaller dogs observed more frequently.

The results of the Siegel-Tukey test (for assemblages with more than 5 samples) suggest that molar size has greater variability than humerus breadth in different chronological periods (Table 5): 9 comparisons found no significant differences in the diversity of values of humerus breadth, and only one (Chalcolithic vs. Roman) had highly significant differences $(\mathrm{p}<0.01)$, compared to 5 comparisons with high significant differences $(\mathrm{p}<0.01)$ and 7 comparisons with no significant differences on the first molar. Interestingly, the length of $\mathrm{M}_{1}$ is more homogeneous in Chalcolithic dogs than in any other periods.

\subsection{Genetic analyses}

We were able to recover DNA from a total of 15 Canis remains, as follows: Thamusida, Morocco (Mauretania Tingitana), $\mathrm{n}=1$; Monte Molião, Portugal (Lusitania), $\mathrm{n}=3$, and Lugo, Spain (Tarraconensis), $\mathrm{n}=11$. None of the controls showed any signs of contamination. Table 4 summarizes the samples analysed for ancient DNA.

Mitochondrial DNA data comprised sequences of 109-181 nucleotides and a total of 17 variable nucleotide sites. We observed five dog mitochondrial haplotypes and detected a single new variant, in Portugal, after comparison with data for extant dogs. These ancient haplotypes could be grouped into two of the major mtDNA lineages observed in extant dogs, i.e., clades A and D (Fig. 5).

More precisely, in Roman times, we detected dog remains carrying haplotypes that belong to mtDNA clades $A(n=12$ : Portugal 3 , Spain 8 and Morocco 1$)$ and $D(n=3$, Spain) (Fig. 6). Interestingly, the older samples from Portugal, which are not contemporaneous with neither African nor Spanish samples, show two different haplotypes within clade A. One sequence (from Monte Molião Portugal, LYEP60) is considered a singleton and is not represented in extant dogs. So far, neither clade C nor B haplotypes were detected in the Roman dogs studied (Fig. 6). In Lugo, northwest Spain, we detect the highest number of haplotypes. These haplotypes differed by up to 7 nucleotides. Evidence for the presence of clade D in the Iberian Peninsula first appears in archaeological dog remains from Roman Spain. 


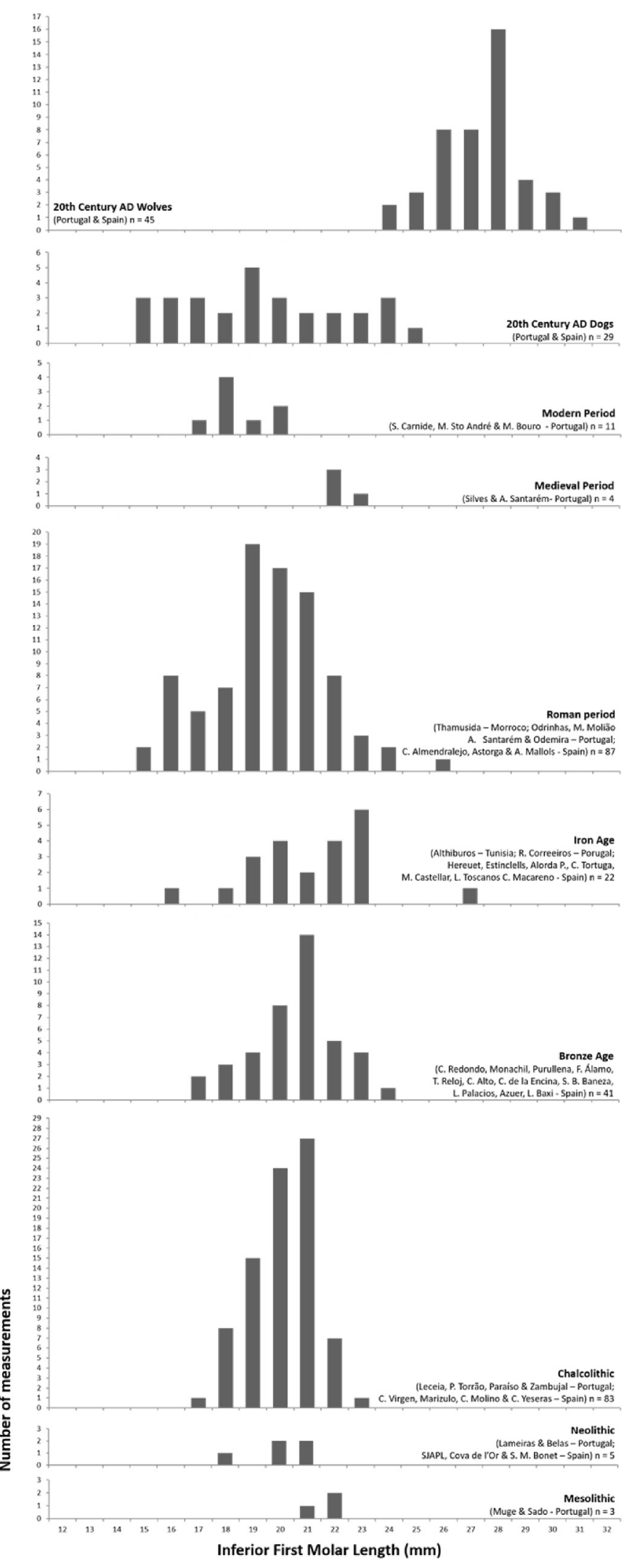

Fig. 3. Stacked histograms with measurements for the length of the lower first molar $(\mathrm{mm})$ of dogs and wolves from the Iberian Peninsula. A diachronic view from several archaeological sites in Iberia and North Africa are compared with measurements from reference skeletal collections (20th century). For more details about these sites and samples see Table 1. [Chalcolithic - 5,000-4,000 years cal BP; Neolithic 7,500-5,000 years cal BP; Mesolithic $-8,000-7,500$ years cal BP].

\section{Discussion}

Teeth and bones generally preserve well in archaeological sites and can provide information about ancient animals using osteometrical and genetic analyses. The first lower molar generally provides a distinction between dogs and wolves (Tchernov and Valla, 1997; Detry and Cardoso, 2010), and it is a useful element also to assess the degree of variability in size and shape of canid populations.

The lengths of the lower molars $\left(\mathrm{M}_{1}\right)$ and the breadths of long bones of the Canis remains analysed in this study clearly show the wide variability of dog morphotypes in the Roman period, which include small sized "dwarf dogs". The variability attested in Roman times is not observed in earlier periods, perhaps with the exception of the Iron Age. Only present-day dogs have a larger variability of sizes and shapes than the Roman ones.

In many organisms, the coefficient of variation (CV) for different traits in natural populations lies between 4 and 10\% (Simpson et al., 1960). For the Roman period as well as for Iron Age and extant dogs, the CV is greater than $10 \%$, as shown in the CV of $M_{1}$ length and distal humerus breadth (Tables 1 and 2). This is compatible with a high level of phenotypic variability, as a result of a strong artificial selection for these phenotypes indicating that human-directed selection pressure and consequent morphological changes were well established in Roman dogs. Such variability was expected since it has been observed in different areas of the Roman empire, namely in England (Bennett and Robert, 2016), North Africa (MacKinnon, 2010) and Iberia (Boessneck and von den Driesch, 1980; Altuna and Mariezkurrena, 1992; Colominas, 2015). A reduction of the $\mathrm{CV}$ after the Roman period also appears to be evident. This can be related to the absence of extreme dogs that only appear again in the 20th century due to artificial selection mainly for aesthetical purposes.

Regarding the genetic analysis, the site of Lugo provided most of the samples analysed $(n=11)$. Thus, in this site, higher mtDNA diversity was observed. Other than the number of samples, the fact that they date from Late Roman times may also have had an influence. To our knowledge, this is the first time that the presence of clade D haplotypes is attested among historic dogs from Iberia. This maternal lineage possibly originates in the Near-East, and has been detected in South-Eastern and Central Europe as early as the Neolithic period (Pionnier-Capitan, 2010). In Iberia, the detection of the first dog D-haplotypes occurs much later. The dog remains from Lugo are dated to Late Roman times-3rd-4th century AD (ca. 1,600-1,700 years ago)-but this haplotype could have come to the Iberian Peninsula any time after the Neolithic, given the continuous human contacts along the Mediterranean since then. This includes early contacts (Davis and Simões, 2016; Isern et al., 2017) as well as the more intense Mediterranean trade in the Iron Age, significantly Phoenicians. This is supported by the presence of numerous colonies and imports along the Southern coast of the Iberian Peninsula and North African (Aranegui, 2016; Aubet, 1987; Ponsich, 1968). First contacts between Iberia and North Africa date of much earlier, at least since the Early Iberian Neolithic (Martínez-Sánchez et al., 2017), probably with a diffusion of farming across the Straits of Gibraltar following a North-toSouth direction (from Iberia to North Africa) (Zilhão, 2014). A more comprehensive sampling may reveal an earlier presence of clade D (and eventually other clades) in the Iberian Peninsula and North Africa.

The presence of dogs carrying more distinct mtDNA lineages in Lugo may also be explained by the fact that it was an administratively and politically very important Roman city (Rodríguez Colmenero, 2011). Considering the sites studied here, Lugo was probably the one with more contacts with other parts of the Roman 


\section{0th Century Wolves}

(Portugal) $n=30$
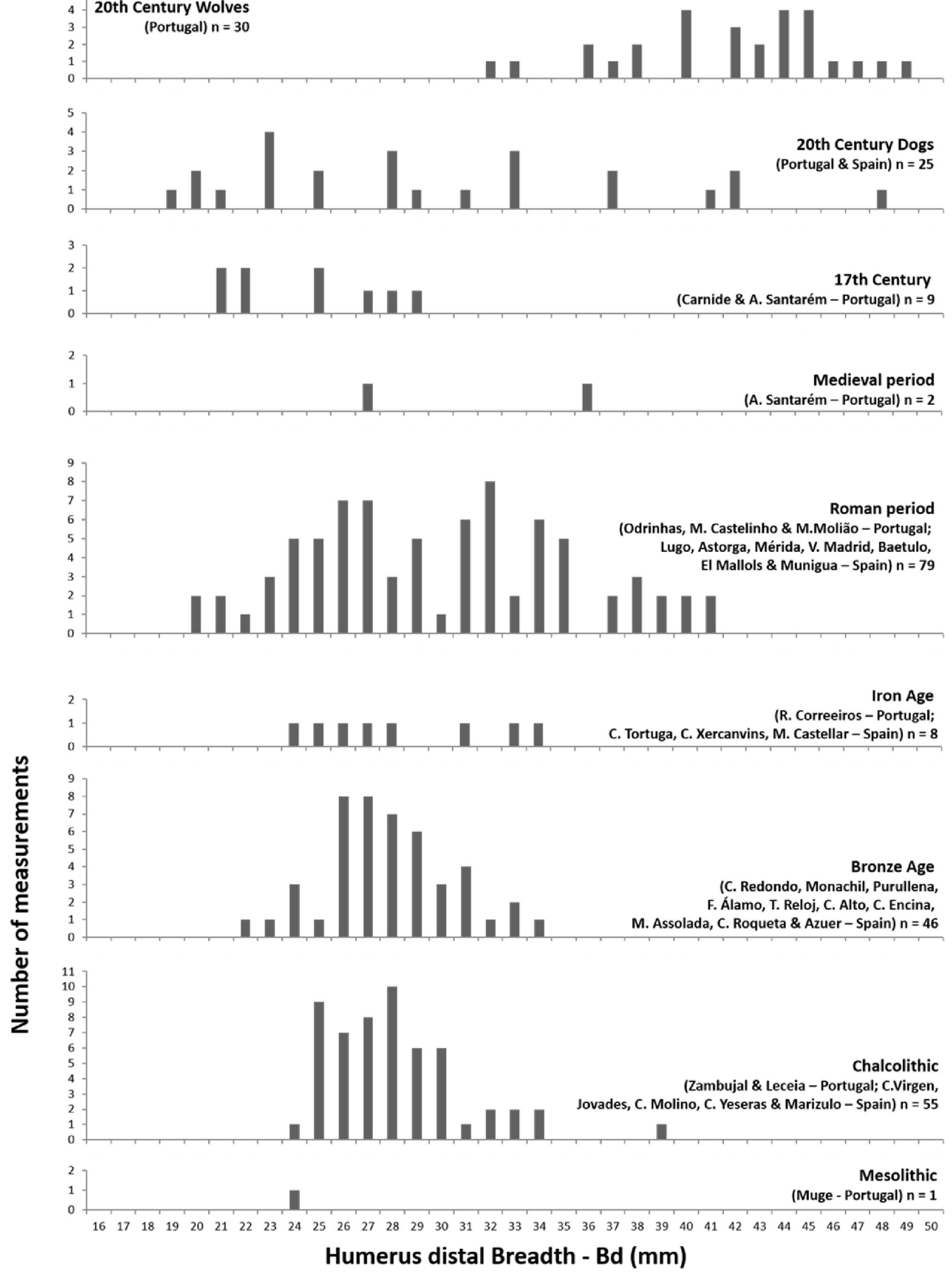

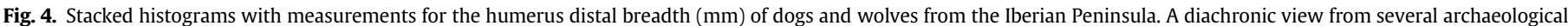

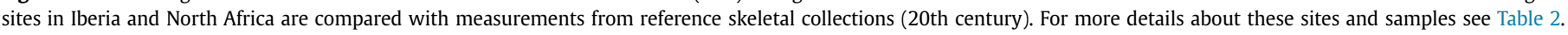
[Chalcolithic - 5,000-4,000 years cal BP; Neolithic - 7,500-5,000 years cal BP; Mesolithic $-8,000-7,500$ years cal BP]. 
Table 5

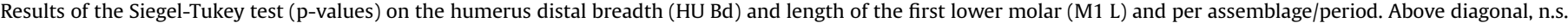
stands for non-significant $(p>0.05),{ }^{*}=p<0.05,{ }^{* *}=p<0.01,{ }^{* * *}=\mathrm{p}<0.001$.

\begin{tabular}{|c|c|c|c|c|c|c|c|}
\hline HU Bd & Chalcolithic & Bronze & Iron & Roman & Modern & Present-day & Number of measurements \\
\hline Chalcolithic & & n.s. & n.s. & $* *$ & n.s. & $*$ & 55 \\
\hline Bronze & 0.9375 & & n.s. & $*$ & n.s. & * & 46 \\
\hline Iron & 0.2876 & 0.3804 & & n.s. & n.s. & * & 8 \\
\hline Roman & 0.005013 & 0.02842 & 0.3702 & & n.s. & $*$ & 79 \\
\hline Modern & 0.1067 & 0.1327 & 0.5966 & 0.7203 & & n.s. & 9 \\
\hline Present-day & 0.01566 & 0.04019 & 0.03377 & 0.029 & 0.2261 & & 25 \\
\hline M1 L & Chalcolithic & Bronze & Iron & Roman & Modern & Present-day & Number of measurements \\
\hline Chalcolithic & & n.s. & ** & $* *$ & $* *$ & ** & 83 \\
\hline Bronze & 0.2019 & & * & n.s. & n.s. & $* *$ & 41 \\
\hline Iron & 0.001734 & 0.03958 & & n.s. & n.s. & n.s. & 22 \\
\hline Roman & 0.001105 & 0.3372 & 0.1661 & & n.s. & $*$ & 87 \\
\hline Modern & 0.00929 & 0.221 & 0.4914 & 0.7114 & & * & 11 \\
\hline Present-day & 0.009162 & 0.003261 & 0.09402 & 0.02602 & 0.03784 & & 29 \\
\hline
\end{tabular}

Empire. Additionally, the detection of the less frequent clade D may echo the consolidation of distinct dog types, as we describe herein for this period. Our results show the presence and breeding of dogs of distinct mtDNA haplogroups, A and D, in Iberia continuously for over 1,600 years.

Samples from Monte Molião, dated to the 1st cent. BC - 1st cent. AD (ca. 2,000 years ago), also reveal interesting aspects of the genetic composition of dog populations in the past. The two mtDNA haplotypes genotyped are not shared with the other dog samples analysed, and one of them consists of a new variant not found in extant dogs. This suggests some level of mtDNA diversity in dogs at this site and that some dog-lineages may have been lost through time. However, we cannot completely discard the possibility that the nucleotide differences found between these single haplotypes and the others results from some level of DNA degradation. In particular, the Monte Molião LYEP60 singleton (a mtDNA sequence found only in one individual), is defined by a nucleotide position that exhibits a thymine (T) while all others exhibit a cytosine (C), which could be a result of damage. In this case, thymine was the prevalent nucleotide in 79 out of the 110 reads for this sample.

The mtDNA sequence of the African dog specimen belongs to clade $A$, which is nowadays the most common lineage found in dogs worldwide, including North Africa (Boyko et al., 2009) and Iberia (Pires et al., 2006). Here we contribute only one sample from Thamusida: interestingly, it shared a clade A haplotype with three other samples from Lugo. This result may indicate that either this was a common lineage in each of these regions or the existence of gene flow between dogs from these regions. Dogs could have been easily transported across the Mediterranean by humans following maritime trading routes. There is considerable evidence for maritime trade between North Africa and North Western Iberia in Roman times (e.g. Naveiro López, 1991), that became even more consolidated in the Late Roman period (e.g. Fernández Fernández, 2014). However, the terrestrial routes could also have been relevant, namely through via de la Plata (linking Augusta Emerita Mérida with Asturica Augusta - Astorga) and via XIX (linking Bracara Augusta - Braga with Asturica Augusta through Lucus Augusti (Lugo)) (De Soto, 2013).

Despite its geographic proximity, the Thamusida sample does not reflect evidence for gene flow between dogs from this region and Monte Molião (no haplotype sharing). This is consistent with other archaeological materials (e.g. pottery), that suggest that, during the Republican and the Imperial Roman periods, imports at Monte Molião from North Africa mainly originated in the province of Africa proconsularis (present-day Tunisia) (Arruda, 2007; Arruda and Sousa, 2013). Nevertheless, this may also be related to the limited sampling in both sites and possible genetic drift.

Fig. 1, as well as data from Bennett and Robert (2016), show that Roman iconography reflects a large amount of morphological variability in dogs. The Roman mosaics from Conímbriga, a very important city in Roman Lusitania (Portugal), show several dog coat colours and even different shapes of the cranium (Fig. 1). These are probably accurate representations of Roman dogs, although we cannot be certain about their geographical origin. The artists that produced these mosaics could be itinerant specialists inspired by local or foreign models. In Conímbriga there are evidences that the artisans are local and the mosaics with the dogs are described as being depictions of the servants of the owner of the house (Correia, 2013). Additionally, various shapes of dogs are represented in ceramic decorations of the sigillata type found in the Iberian Peninsula (Bennett and Robert, 2016; Bustamante and Detry, 2017). However, taken together, iconographic, zooarchaeological and ancient DNA data, all coincide in reflecting the existence of different dog sizes, shapes and origins in Roman times.

\section{Conclusion}

This study confirms the utility of combining morphological, palaeogenetic and archaeological data to describe past phenotypic and genetic variability of dogs. We detected the presence of various mtDNA lineages during Roman times in Iberia and North Africa, which is in agreement with the documented high morphological diversity of dogs in the iconographic evidence-pottery and mosaics-from these areas. The zooarchaeological study also revealed that the diversity of morphologies was greater in Roman times compared to any other period, with the exception of present-day dogs. This suggests that artificial selection for morphologic traits was well established in Roman times and included lap dogs.

While mtDNA analysis is informative to investigate genetic affinities and demographic changes in domestic animal populations, autosomal DNA (i.e., markers linked to phenotypic traits) is needed to recover signatures of post-domestication changes in inheritable traits due to human selection. Subsequent genetic analysis of the dog specimens described in this study using such markers will allow us to describe some phenotypic traits of Roman dogs for a more comprehensive interpretation of their variability. 


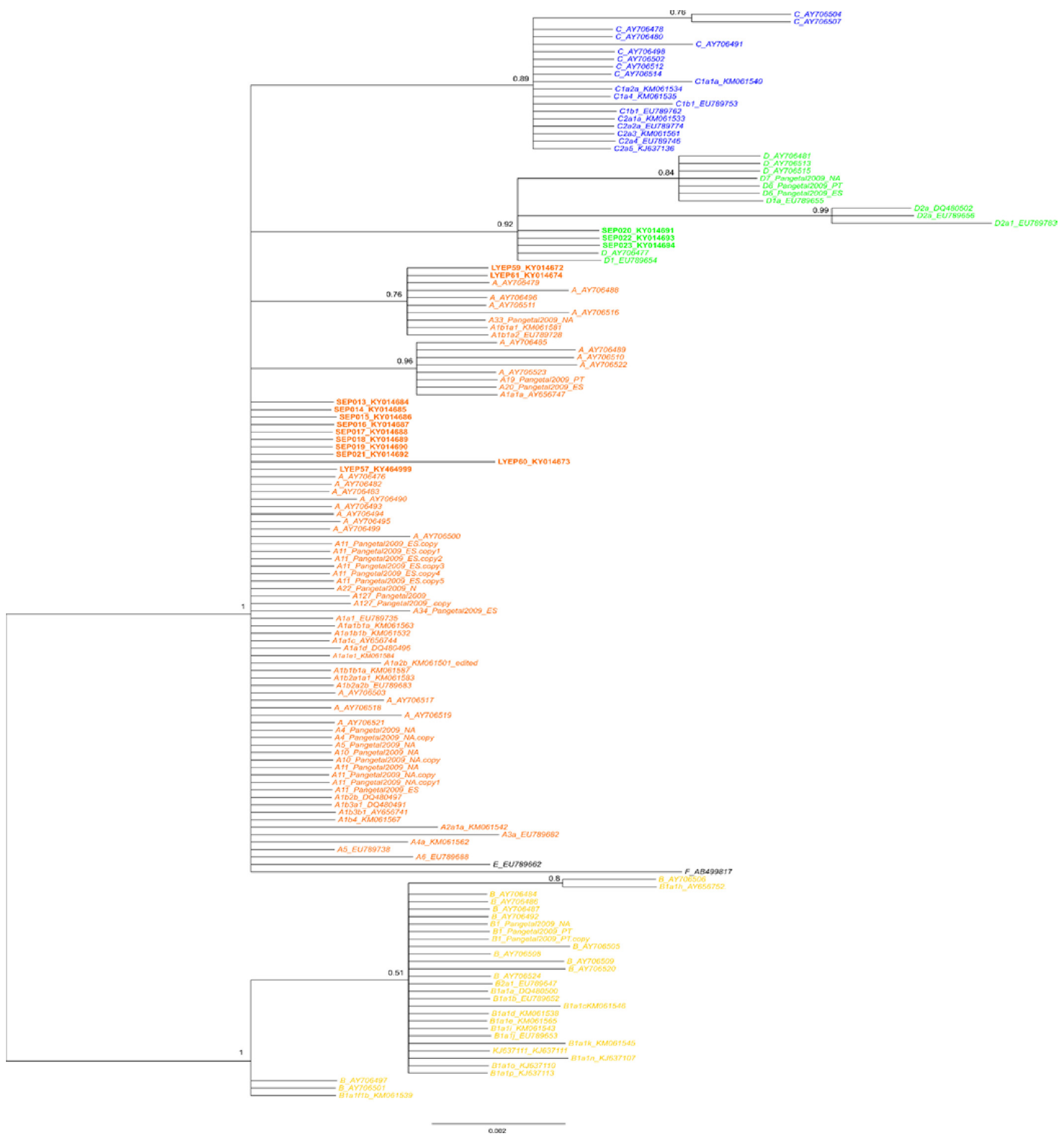

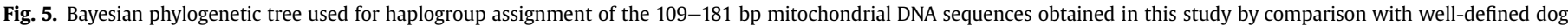

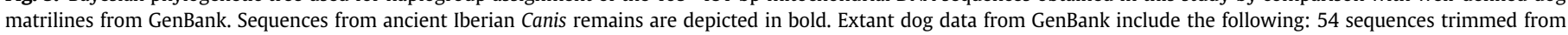

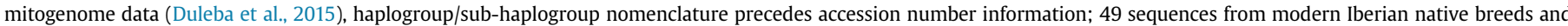

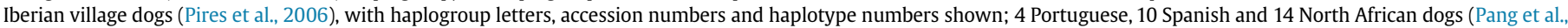

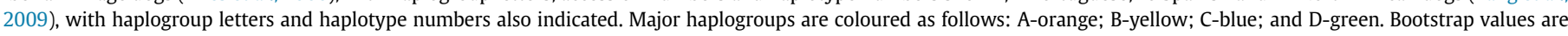
indicated for each node. (For interpretation of the references to colour in this figure legend, the reader is referred to the Web version of this article.) 


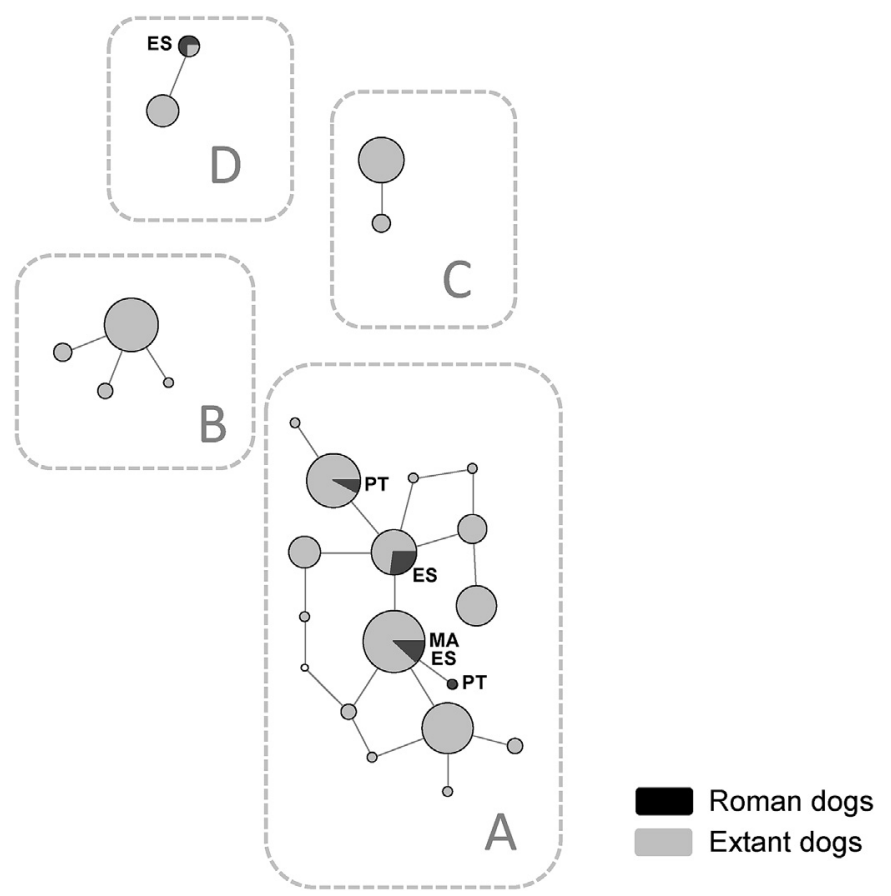

Fig. 6. Median-joining network of mtDNA sequences. Clades A, B, C and D represent the major haplogroups found in extant dogs as defined by mitogenomes in Duleba et al. (2015). Five distinct ancient haplotypes were recovered from Roman dog samples (black) and which clustered with haplotypes A and D of extant dogs (gray). ES refers to haplotypes found in Roman Spain, MA in Morocco and PT in Portugal. The single white dot represents a median vector generated by the software to indicate an expected but unsampled haplotype.

\section{Conflicts of interest}

The authors declare no conflicts of interest.

\section{Acknowledgments}

The authors wish to thank: Virgílio Hipólito Correia of the Conímbriga Museum for photographs and information regarding the Roman mosaics; David Gonçalves for help with the map of the Roman Empire and depiction of the archaeological sites; Javier Heras for zooarchaeological data from Mérida - Calle Almendralejo; to Simon Davis for a critical review of the manuscript and also for revising the English language, and to two anonymous reviewers whose comments contributed greatly to the quality of this manuscript. This study was funded by the FCT (Fundação para a Ciência e a Tecnologia) within the research PTDC/HIS-ARQ/100225/ 2008; and AE Pires grant SFRH/BPD/112653/2015; C Detry grant SFRH/BPD/108326/2015 and C Ginja contract grant IF/00866/2014.

\section{References}

Afgan, E., Baker, D., van den Beek, M., Blankenberg, D., Bouvier, D., Čech, M. Chilton, J., Clements, D., Coraor, N., Eberhard, C., Grüning, B., Guerler, A., Hillman-Jackson, J., Von Kuster, G., Rasche, E., Soranzo, N., Turaga, N., Taylor, J., Nekrutenko, A., Goecks, J., 2016. The Galaxy platform for accessible, reproducible and collaborative biomedical analyses: 2016 update. Nucleic Acids Res. 44, W3-W10. https://doi.org/10.1093/nar/gkw343.

Albizuri, S., 2011. La ofrenda animal durante el Bronce Inicial en Can Roqueta I (Sabadell, Valles Occidental). Arqueozoologia del ritual funerario. Universitat de Girona.

Altschul, S.F., Gish, W., Miller, W., Myers, E.W., Lipman, D.J., 1990. Basic local alignment search tool. J. Mol. Biol. 215, 403-410. https://doi.org/10.1016/S00222836(05)80360-2.

Altuna, J., 1967. Fauna de mamíferos del yacimiento prehistórico de Marizulo (Urnieta), Guipúzcoa. Sociedad de Ciencias Naturales Aranzadi.
Altuna, J., Mariezkurrena, K., 2007. Restos de Macromamíferos de SJAPL. In: Aramburu, J.I.V. (Ed.), San Juan Ante Portam Latinam: Una Inhumación Colectiva Prehistórica En El Valle Medio Del Ebro; Memoria de Las Excavaciones Arqueológicas, 1985, 1990 Y 1991. Diputación Foral de Álava. Departamento de Cultura, pp. 91-97.

Altuna, J., Mariezkurrena, K., 1992. Perros enanos en yacimientos romanos de la Península Ibérica. Archaeofauna 1, 83-86.

Alvar, J., Gordon, R., Rodríguez, C., 2006. The mithraeum at Lugo (Lucus Augusti) and its connection with Legio VII Gemina. J. Rom. Archaeol. 19, 266-277. https:/| doi.org/10.1017/S1047759400006383.

Amberger, G., 1985. Tierknochenfunde vom Cerro Macareno (Sevilla). In: Studien Über Frühe Tierknochenfunde von Der Iberischen Halbinsel, 9. München Universität, München, pp. 6-105.

Aranegui, C., 2016. LIXUS. Del mito a la historia, Barcelona: Bellaterra 2017. Ediciones Bellaterra, Barcelona.

Ardalan, A., Kluetsch, C.F.C., Zhang, A., Erdogan, M., Uhlén, M., Houshmand, M. Tepeli, C., Ashtiani, S.R.M., Savolainen, P., 2011. Comprehensive study of mtDNA among Southwest Asian dogs contradicts independent domestication of wolf, but implies dog-wolf hybridization. Ecol. Evol. 1, 373-385. https://doi.org/ $10.1002 /$ ece 3.35 .

Arruda, A., 2007. Laccobriga: A ocupação romana da Baía de Lagos. Câmra Municipal de Lagos, Lagos.

Arruda, A., Sousa, E., 2013. Ânforas Republicanas de Monte Molião (Lagos, Algarve, Portugal), vol. 21. SPAL, pp. 93-133.

Aubet, M.E., 1987. Tiro y las colonias fenicias de Occidente. Bellaterra.

Bandelt, H.-J., Macaulay, V., Richards, M., 2000. Median networks: speedy construction and greedy reduction, one simulation, and two case studies from human mtDNA. Mol. Phylogenet. Evol. 16, 8-28. https://doi.org/10.1006/ mpev.2000.0792.

Bandelt, H.J., Forster, P., Röhl, A., 1999. Median-joining networks for inferring intraspecific phylogenies. Mol. Biol. Evol. 16, 37-48.

Bennett, D., Campbell, G., Timm, R.M., 2016. The dogs of Roman Vindolanda, Part I: Morphometric techniques useful in differentiating domestic and wild canids. Archaeofauna 25, 79-106.

Bennett, D., Robert, M.T., 2016. The dogs of Roman Vindolanda, Part II: timestratigraphic occurrence, ethnographic comparisons, and biotype reconstruction. Archaeofauna 25, 107-126.

Boessneck, J., von den Driesch, A., 1980. Tierknochenfunde aus vier Südspanischen Höhlen: untersuchung der Tierknochenfunde; Tierknochenfunde aus Sacaojos bei la Bañeza (Prov. León). Stud. über frühe Tierknochenfunde von der Iberischen Halbinsel, vol. 7.

Boessneck, J., von den Driesch, A., Schüle, W., 1969. Die Knochenfunde vom Cerro del Real bei Galera (Prov. Granada); Die Fauna des "Cabezo Redondo" bei Villena (Prov. Alicante). In: Studien Über Frühe Tierknochenfunde von Der Iberischen Halbinsel. München Universität, p. 106.

Botigué, L.R., Song, S., Scheu, A., Gopalan, S., Pendleton, A.L., Oetjens, M., Taravella, A.M., Seregély, T., Zeeb-Lanz, A., Arbogast, R.-M., Bobo, D., Daly, K., Unterländer, M., Burger, J., Kidd, J.M., Veeramah, K.R., 2017. Ancient European dog genomes reveal continuity since the Early Neolithic. Nat. Commun. 8, 16082. https://doi.org/10.1038/ncomms16082.

Boyko, A.R., Boyko, R.H., Boyko, C.M., Parker, H.G., Castelhano, M., Corey, L., Degenhardt, J.D., Auton, A., Hedimbi, M., Kityo, R., Ostrander, E.A., Schoenebeck, J., Todhunter, R.J., Jones, P., Bustamante, C.D., 2009. Complex population structure in African village dogs and its implications for inferring dog domestication history. Proc. Natl. Acad. Sci. U. S. A. 106, 13903-13908. https://doi.org/10.1073/pnas.0902129106.

Bustamante, M., Detry, C., 2017. Cerâmica e animais: representações zoomórficas em Terra Sigillata Hispânica. Actas do Encontro "O mundo animal na romanização da Península Ibérica, Lisboa (in press).

Carreras Monfort, C., 2011. Ánforas romanas de Lugo : comercio romano en el finis terrae. Concello de Lugo, Lugo.

Catagnano, V., 2016. Aproximación Morfométrica e Paleogenética al estudio de la variabilidad de C. l. familiaris en la Península Ibérica desde el Neolítico hasta Época Romana y su Contextualización en el ámbito del Mediterráneo occidental. Universitat Autonòma de Barcelona.

Colominas, L., 2015. Morphometric variability of roman dogs in Hispania Tarraconensis: the case study of the Vila de Madrid Necropolis. Int. J. Osteoarchaeol 26, 897-905. https://doi.org/10.1002/oa.2507.

Colominas, L., 2009. La gestió dels animals al nord-est de la Península Ibèrica entre els segles $\mathrm{V}$ ane. - V dne. Universitat Autònoma de Barcelona.

Correia, V.H., 2013. A Arquitectura doméstica de Conímbriga e as estruturas económicas e sociais da cidade romana. Centro de Estudos Arquelógicos das Universidades de Coimbra e Porto., Coimbra.

Cruz, C., 2007. As Raças Portuguesas de Cães de Gado e de Pastoreio. Aspectos Morfológicos e Comportamentais. Universidade Técnica de Lisboa.

Davis, M., Gonçalves, M., Gabriel, S., 2008. Animal remains from a Moslem period (12th/13th century AD) lixeira (garbage dump) in Silves, Algarve. Port. Rev. Port. Arqueol. 11, 183-258.

Davis, S., Gonçalves, A., 2017. Animal remains from the 4th-5th century AD well at São Miguel de Odrinhas, Sintra, Portugal: tiny sheep and a dwarf dog. Rev. Port. Arqueol. 20, 139-156.

Davis, S.J.M., 2006. Faunal remains from Alcáçova de Santarém (Portugal). Instituto Português de Arqueologia, Lisboa.

Davis, S.J.M., Simões, T., 2016. The Velocity of Ovis in Prehistoric Times: the Sheep Bones from Early Neolithic Lameiras, Sintra, Portugal. Monogr. AAP, pp. 51-66. 
Davis, S.J.M., Vilhena, J., 2017. Animal remains from Iron Age and Roman Odemira, Portugal. Archaeofauna 26, 199-217.

Daza, A., 2015. La fauna en el Calcolítico de la región de Madrid: los depósitos de canes (Master thesis). Universidad Autonoma de Madrid. Ano Academico 20112012.

De Grossi Mazzorin, J., De Venuto, G., 2010. Ricerche archeozoologiche a Thamusida (Marocco): allevamento, alimentazione e ambiente di un insediamento mauro e di una città romana. In: Osiride, R.E. (Ed.), Atti Del V Convegno Nazionale Di Archeozoologia. Rovereto, pp. 389-393.

De Grossi Mazzorin, J., Tagliacozzo, A., 2000. Morphological and osteological changes in the dog from the Neolithic to the Roman period in Italy. In: Crockford, S. (Ed.), Dogs through Time;: an Archaeological Perspective ;: Proceedings of the 1st ICAZ Symposium on the History of the Domestic Dog. Eight Congress of the International Council for Archaeozoology (ICAZ98), August 2329, 1998. British Archaeological Reports (International Series), Oxford, Victoria, B.C., Canada, pp. 141-161.

De Grossi Mazzorin, J., Tagliacozzo, A., 1998. Dog remains in Italy from the Neolithic to the Roman period. Anthropozoologica 25-26, 429-440.

De Soto, P., 2013. Los sistemas de transporte romanos y la configuración territorial en el noroeste peninsular. In: Morais, R., Granja, H., Morillo, A. (Eds.), O Irado Mar Atlantico. O Naufrágio Bético Augustano de Esposende (Norte de Portugal). Braga, pp. 179-210.

Detry, C., Arruda, A.M., 2013. A fauna da Idade do Ferro e da Época Romana de Monte Molião (Lagos, Algarve): continuidades e rupturas na dieta alimentar. Rev. Port. Arqueol. 213-226.

Detry, C., Cardoso, J.L., 2010. On some remains of dog (Canis familiaris) from the Mesolithic shell-middens of Muge. Port. J. Archaeol. Sci. 37, 2762-2774. https:// doi.org/10.1016/j.jas.2010.06.011.

Detry, C., Cardoso, J.L., Bugalhão, J., 2016. A alimentação em Lisboa no decurso da Idade do Ferro: resultados das escavacões realizadas no Núcleo Arqueológico da Rua dos Correeiros (Lisboa, Portugal), vol. 25. SPAL. Rev. Prehist. y Arqueol. la Univ. Sevilla, pp. 67-82

Duleba, A., Skonieczna, K., Bogdanowicz, W., Malyarchuk, B., Grzybowski, T., 2015. Complete mitochondrial genome database and standardized classification system for Canis lupus familiaris. Forensic Sci. Int. Genet. 19, 123-129. https:// doi.org/10.1016/j.fsigen.2015.06.014.

Fernandez-Rodriguez, C., 2000. Los macromamíferos en los yacimentos arqueológicos del Noroeste Penisular: Un Estudio Económico. Universidade de Santiago de Compostela. Facultad de Xeografía e Historia.

Fernández-Rodriguez, C., 2003. Ganadería, caza y animales de compañía en la Galicia romana: estudio arqueozoológico. Brigantium 15, 238.

Fernández Fernández, A., 2014. El comercio tardoantiguo (ss. IV - VII) en el noroeste peninsular a través del registro cerámico de la Ría de Vigo. Archaeopress, Oxford.

Frantz, L.A.F., Mullin, V.E., Pionnier-Capitan, M., Lebrasseur, O., Ollivier, M., Perri, A., Linderholm, A., Mattiangeli, V., Teasdale, M.D., Dimopoulos, E.A., Tresset, A., Duffraisse, M., McCormick, F., Bartosiewicz, L., Gál, E., Nyerges, É.A., Sablin, M.V. Bréhard, S., Mashkour, M., Bălășescu, A., Gillet, B., Hughes, S., Chassaing, O., Hitte, C., Vigne, J.-D., Dobney, K., Hänni, C., Bradley, D.G., Larson, G., 2016. Genomic and archaeological evidence suggest a dual origin of domestic dogs. Science 352, 1228-1231. https://doi.org/10.1126/science.aaf3161.

Friesch, K., 1987. Die Tierknochenfunde von Cerro de la Encina bei Monachil, Provinz Granada: (Grabungen 1977-1984). In: Studien Über Frühe Tierknochenfunde von Der Iberischen Halbinsel. München Universität, p. 135.

Galtier, N., Gouy, M., Gautier, C., 1996. SEAVIEW and PHYLO_WIN: two graphic tools for sequence alignment and molecular phylogeny. Bioinformatics $12,543-548$. https://doi.org/10.1093/bioinformatics/12.6.543.

Harcourt, R.A., 1974. The dog in prehistoric and early historic britain. J. Archaeol. Sci. 1, 151-175. https://doi.org/10.1016/0305-4403(74)90040-5.

Horard-Herbin, M.-P., Tresset, A., Vigne, J.-D., 2014. Domestication and uses of the dog in western Europe from the Paleolithic to the Iron Age. Anim. Front. 4, 23-31. https://doi.org/10.2527/af.2014-0018.

Huelsenbeck, J.P., Ronquist, F., Nielsen, R., Bollback, J.P., 2001. Bayesian inference of phylogeny and its impact on evolutionary biology. Science 294 (80), 2310-2314. https://doi.org/10.1126/science.1065889.

Isern, N., Zilhão, J., Fort, J., Ammerman, A.J., 2017. Modeling the role of voyaging in the coastal spread of the early Neolithic in the west Mediterranean. Proc. Natl. Acad. Sci. 114, 897-902. https://doi.org/10.1073/pnas.1613413114.

Lauk, H., 1976. Tierknochenfunde aus bronzezeitlichen Siedlungen bei Monachil und Purullena (Provinz Granada). In: Studien Über Frühe Tierknochenfunde von Der Iberischen Halbinsel. München Universität.

Leonard, J.A., Wayne, R.K., Wheeler, J., Valadez, R., Guillén, S., Vilà, C., 2002. Ancient DNA evidence for old world origin of new world dogs. Science 298 (80).

MacKinnon, M., 2010. “Sick as a dog": zooarchaeological evidence for pet dog health and welfare in the Roman world. World Archaeol. 42, 290-309. https://doi.org/ $10.1080 / 00438241003673011$.

Martínez-Sánchez, R.M., Vera-Rodriguez, J.C., Pérez-Jordà, G., Peña-Chocarro, L., Bokbot, Y., 2017. The beginning of the Neolithic in northwestern Morocco. Quat. Int. https://doi.org/10.1016/J.QUAINT.2017.05.052.

Milz, H., 1986. Die Tierknochenfunde aus drei argarzeitlichen Siedlungen in der Provinz Granada (Spanien). In: Studien Über Frühe Tierknochenfunde von Der Iberischen Halbinsel. München Universität, p. 149.

Morales, M., López Arrabé, J., Casado Violat, S., Llorente Rodriguez, L., 2015. Caracterización morfométrica de los perros de la unidad estratigráfica 26 del pozo-depósito de la Tabacalera (Canis familiaris). In: Fernández Ochoa, C., Orejas
Saco del Valle, A., García Díaz, P., Gil Sendino, F. (Eds.), La Fábrica de Tabacos de Gijón. Arqueología E Historia de Un Espacio Milenario. Ayuntamiento de Gijón, Gijón, pp. 238-245.

Naveiro López, J., 1991. El comercio antiguo en el N.W. peninsular. Sada, A Coruña. Oleiro, J.M.B., 1992. Corpus dos mosaicos romanos de Portugal, I. In: Conímbriga. Casa Dos Repuxos. Conimbriga. Museu Monográfico, pp. 117-125.

Ollivier, M., Tresset, A., Bastian, F., Lagoutte, L., Axelsson, E., Arendt, M.-L. Bălășescu, A., Marshour, M., Sablin, M.V., Salanova, L., Vigne, J.-D., Hitte, C. Hänni, C., 2016. Amy2B copy number variation reveals starch diet adaptations in ancient European dogs. Open Sci. 3.

Ollivier, M., Tresset, A., Hitte, C., Petit, C., Hughes, S., Gillet, B., Duffraisse, M. Pionnier-Capitan, M., Lagoutte, L., Arbogast, R.-M., Balasescu, A., Boroneant, A., Mashkour, M., Vigne, J.-D., HÃanni, C., 2013. Evidence of coat color variation sheds new light on ancient canids. PLoS One 8, e75110. https://doi.org/10.1371/ journal.pone.0075110.

Pang, J.-F., Kluetsch, C., Zou, X.-J., Zhang, A., Luo, L.-Y., Angleby, H., Ardalan, A., Ekström, C., Sköllermo, A., Lundeberg, J., Matsumura, S., Leitner, T., Zhang, Y.-P., Savolainen, P., 2009. mtDNA data indicate a single origin for dogs south of Yangtze River, less than 16,300 years ago, from numerous wolves. Mol. Biol. Evol. 26, 2849-2864. https://doi.org/10.1093/molbev/msp195.

Peters, J., 1998. Römische Tierhaltung und Tierzucht: eine Synthese aus archäozoologischer Untersuchung und schriftlich-bildlicher Überlieferung, vol. 5 Passauer Universitätsschriften zur Archäologie, Westfalia.

Pilot, M., Greco, C., vonHoldt, B.M., Jędrzejewska, B., Randi, E., Jędrzejewski, W. Sidorovich, V.E., Ostrander, E.A., Wayne, R.K., 2014. Genome-wide signatures of population bottlenecks and diversifying selection in European wolves. Hered. (Edinb) 112, 428-442. https://doi.org/10.1038/hdy.2013.122.

Pionnier-Capitan, M., 2010. La domestication du chien en Eurasie: étude de la diversité passée, approches ostéoarchéologiques, morphométriques et paléogénétiques. École normale supérieure, Lyon. http://www.theses.fr.

Pires, A., Ouragh, L., Kalboussi, M., Matos, J., Petrucci-Fonseca, F., Bruford, M.W., 2006. Mitochondrial DNA sequence variation in Portuguese native dog breeds: diversity and phylogenetic affinities. J. Hered. 97, 318-330. https://doi.org/ 10.1093/jhered/esl006.

Pires, F., Cardoso, J., Petrucci-Fonseca, F., 2001. Estudo arqueozoológico dos Carnívoros do povoado pré-histórico de Leceia (Oeiras). Estud. Arqueol. OEIRAS 10 $183-247$

Ponsich, M., 1968. Alfarerías de época fenicia y púnico-mauritana en Kuass (Arcila, Marruecos). Universidad de Valencia, Valência.

Rambaut, A., Suchard, M.A., Xie, D., Drummond, A.J., 2014. Tracer | BEAST [WWW Document]. http://beast.bio.ed.ac.uk/tracer (Accessed 7.14.17).

Rodríguez, C., Cordeiro, L., 2014. La domus del Mitreo en Lucus Augusti. In: Álvarez Martínez, J., Nogales Basarrate, T., Rodá, I. (Eds.), Centro Y Periferia En El Mundo Clásico. Actas Del XVIII Congreso Internacional de Arqueología Clásica. Museo Nacional de Arte Romano, Mérida, pp. 1125-1128.

Rodríguez Cao, C., 2006. A Domus do Mitreo. Universidade de Santiago de Compostela, A Coruña.

Rodríguez Colmenero, A., 2011. Lucus Augusti. A Cidade Romano-Xermánica Da Fisterra Ibérica. Xénese E Evolución Histórica 14 A.C- 711 D.C. Concello de Lugo, Lugo.

Ronquist, F., Huelsenbeck, J.P., 2003. MrBayes 3: Bayesian phylogenetic inference under mixed models. Bioinformatics 19, 1572-1574.

Sanchis, A., Sarrión, I., 2004. Restos de cánidos (Canis familiaris ssp.) en yacimientos valencianos de la Edad del Bronce. Arch. Prehist. Levantina 25, 161-198.

Savolainen, P., Zhang, Y., Luo, J., Lundeberg, J., Leitner, T., 2002. Genetic evidence for an East Asian origin of domestic dogs. Science 298 (80), 1610-1613. https:/ doi.org/10.1126/science.1073906.

Siegel, S., Tukey, J.W., 1960. A nonparametric sum of ranks procedure for relative spread in unpaired samples. J. Am. Stat. Assoc. 55, 429-445. https://doi.org 10.1080/01621459.1960.10482073.

Simpson, G., Roe, A., Lewontin, R., 1960. Quantitative Zoology. Harcourt, New York.

Svensson, E.M., Anderung, C., Baubliene, J., Persson, P., Malmström, H., Smith, C. Vretemark, M., Daugnora, L., Götherström, A., 2007. Tracing genetic change over time using nuclear SNPs in ancient and modern cattle. Anim. Genet. 38 378-383. https://doi.org/10.1111/j.1365-2052.2007.01620.x.

Tchernov, E., Valla, F., 1997. Two new dogs, and other natufian dogs, from the Southern Levant. J. Archaeol. Sci. 24, 65-95. https://doi.org/10.1006/ jasc.1995.0096.

Valenzuela-Lamas, S, 2016. Alimentation et élevage à Althiburos à partir des restes fauniques. In: Kallala, N., Sanmartí, J., Belarte, M.C. (Eds.), Althiburos II. L'aire Du Capitole et La Nécropole Méridionale: Études. Documenta 28. Tarragona, pp. 421-448.

Valenzuela-Lamas, S., 2010. Alimentació i artesanat. Els macromamífers de la bassa del poblat ibèric dels Estinclells (Verdú, Urgell). Urtx, vol. 24, pp. 69-82.

Valenzuela-Lamas, S., 2008. Gestió dels recursos animals i dieta càrnia a la costa central de Catalunya durant la Protohistòria (s. VII-III aC). Universitat de Barcelona.

Valenzuela-Lamas, S., Fabião, C., 2012. Ciervos, ovejas y vacas: el registro faunístico de Mesas do Castelinho (Almodôvar) entre la edad del hierro y época romana. In: V Encontro de Arqueologia Do Sudoeste Peninsular, pp. 413-432.

von den Driesch, A., 1976. A Guide to the Measurement of Animal Bones from Archaeological Sites. Peabody Museum of Archaeology and Ethnology. Harvard University.

von den Driesch, A., 1973. Nahrungsrcste tierischer Herkunft aus einer taríessíschen und einer spatbronzezeitlichen bis iberischen Siediungm Südspanien. In 
Stüdien Über Frühe Tierknochenfunde von Der Iberischen Halbinsel 4. München Universität, p. 9.

von den Driesch, A., 1972. Osteoarchäologische Untersuchungen auf der Iberischen Halbinsel. In: Studien Über Frühe Tierknochenfunde von Der Iberischen Halbinsel. München Universität, p. 267.

von den Driesch, A., Boessneck, J., 1976. Die fauna vom Castro do Zambujal. In: Studien Über Frühe Tierknochenfunde von Der Iberischen Halbinsel. München Universität, pp. 4-129.

von den Driesch, A., Boessneck, J., Kokabi, M., Schäffer, J., Amberger, G., 1985.
Tierknochenfunde aus der Bronzezeitlichen Höhensiedlung Fuente Álamo, Provinz Almeria. In: Studien Über Frühe Tierknochenfunde von Der Iberischen Halbinsel. München Universität, p. 105.

Wayne, R.K., 2001. Consequences of domestication: morphological diversity of the dog. In: Ruvinsky, A., Sampson, J. (Eds.), The Genetics of the Dog. CABI Publishing, Oxford, pp. 43-60.

Zilhão, J., 2014. Early prehistoric navigation in the western Mediterranean: implications for the Neolithic transition in Iberia and the Maghreb. Eurasian Prehistory $11,185-200$ 